Article

\title{
Peer-Reviewed Literature on Grain Legume Species in the WoS (1980-2018): A Comparative Analysis of Soybean and Pulses
}

\author{
Marie-Benoît Magrini ${ }^{1, *(\mathbb{D})}$, Guillaume Cabanac ${ }^{2}$ (), Matteo Lascialfari ${ }^{1}$, Gael Plumecocq ${ }^{1}$, \\ Marie-Josephe Amiot ${ }^{3}{ }^{(D}$, Marc Anton ${ }^{4}$, Gaelle Arvisenet ${ }^{5}$, Alain Baranger ${ }^{6}$, \\ Laurent Bedoussac $^{7}{ }^{(D}$, Jean-Michel Chardigny ${ }^{8}{ }^{D}$, Gérard Duc ${ }^{9}$, Marie-Hélène Jeuffroy ${ }^{10}$, \\ Etienne-Pascal Journet ${ }^{1,11}$, Hervé Juin ${ }^{12}$, Colette Larré ${ }^{4}$, Hugues Leiser ${ }^{13}$, Valérie Micard ${ }^{14}$, \\ Dominique Millot ${ }^{9}$, Marie-Laure Pilet-Nayel ${ }^{6}$, Christophe Nguyen-Thé ${ }^{15}$, Tristan Salord ${ }^{1}$, \\ Anne-Sophie Voisin ${ }^{9}$, Stéphane Walrand ${ }^{16}$ and Jacques Wery ${ }^{17}$ \\ 1 AGIR, INRA, Université de Toulouse, 31326 Castanet-Tolosan, France; matteo.lascialfari@inra.fr (M.L.); \\ gael.plumecocq@inra.fr (G.P.); etienne-pascal.journet@inra.fr (E.-P.J.); tristan.salord@inra.fr (T.S.) \\ 2 IRIT, Université de Toulouse, 31062 Toulouse, France; guillaume.cabanac@univ-tlse3.fr \\ 3 MOISA, CIRAD, CIHEAM-IAAM, INRA, Montpellier SupAgro, Université Montpellier, 34060 Montpellier, \\ France; marie-josephe.amiot-carlin@inra.fr \\ 4 BIA, INRA, 44000 Nantes, France; marc.anton@inra.fr (M.A.); colette.larre@inra.fr (C.L.) \\ 5 CSGA, AgroSup Dijon, CNRS, INRA, Université Bourgogne-Franche-Comté, 21000 Dijon, France; \\ gaelle.arvisenet@agrosupdijon.fr \\ 6 IGEPP, INRA, Agrocampus-Ouest, Université Rennes 1, 35653 Le Rheu, France; alain.baranger@inra.fr (A.B.); \\ marie-laure.pilet-nayel@inra.fr (M.-L.P.-N.) \\ 7 AGIR, INRA, ENSFEA, Université de Toulouse, 31326 Castanet-Tolosan, France; laurent.bedoussac@inra.fr \\ 8 DPTI, INRA, 75338 Paris, France; jean-michel.chardigny@inra.fr \\ 9 Agroecologie, INRA, AgroSup Dijon, Université Bourgogne France-Comté, 21000 Dijon, France; \\ gerard.duc@inra.fr (G.D.); dominique.millot@inra.fr (D.M.); anne-sophie.voisin@inra.fr (A.-S.V.) \\ 10 Agronomie, INRA, AgroparisTech, Université Paris-Saclay, 78850 Thiverval-Grignon, France; \\ marie-helene.jeuffroy@inra.fr \\ 11 LIPM, Université de Toulouse, INRA, CNRS, 31326 Castanet-Tolosan, France \\ 12 EASM, INRA, 17700 Surgères, France; herve.juin@inra.fr \\ 13 IST, INRA, 84140 Avignon, France; hugues.leiser@inra.fr \\ 14 IATE, INRA, Montpellier SupAgro, CIRAD, Université Montpellier, 34060 Montpellier, France; \\ valerie.micard@supagro.fr \\ 15 SQPOV, INRA, 84140 Avignon, France; christophe.nguyen-the@inra.fr \\ 16 INRA, UNH, Unité de Nutrition Humaine, CRNH Auvergne, Université Clermont Auvergne, 63001 \\ Clermont-Ferrand, France; stephane.walrand@inra.fr \\ 17 ICARDA, Ismail El-Shaaer Building, Maadi 11728, Egypt; J.Wery@cgiar.org \\ * Correspondence: marie-benoit.magrini@inra.fr; Tel.: +33-561-285-422
}

Received: 25 September 2019; Accepted: 22 November 2019; Published: 2 December 2019

check for updates

\begin{abstract}
Grain-legume crops are important for ensuring the sustainability of agrofood systems. Among them, pulse production is subject to strong lock-in compared to soya, the leading worldwide crop. To unlock the situation and foster more grain-legume crop diversity, scientific research is essential for providing new knowledge that may lead to new development. Our study aimed to evaluate whether research activity on grain-legumes is also locked in favor of soya. Considering more than 80 names grouped into 19 main grain-legume species, we built a dataset of 107,823 scholarly publications (articles, book, and book chapters) between 1980 and 2018 retrieved from the Web of Science (Clarivate Analytics) reflecting the research activity on grain-legumes. We delineated 10 scientific themes of interest running the gamut of agrofood research (e.g., genetics, agronomy, and nutrition). We indexed grain-legume species, calculated the percentage of records for each one, and conducted several analyses longitudinally and by country. Globally, we found an unbalanced research
\end{abstract}


output: soya remains the main crop studied, even in the promising field of food sciences advanced by FAO as the "future of pulses". Our results raise questions about how to align research priorities with societal demand for more crop diversity.

Keywords: knowledge dynamics; science and technology studies (STS); research trajectories; scientometrics; bibliometric data; agricultural sciences; food sciences; sustainability

\section{Introduction}

A major challenge for agriculture is to greatly reduce the use of synthetic inputs and to rely on more ecological processes. To foster sustainability, increasing crop diversity with legumes has been advanced as a major driver of change [1-3]. More legume cultivation will provide considerable ecological services, in addition to their nutritional advantages, as legumes enable a renewable input of nitrogen $(\mathrm{N})$ into agricultural soils through symbiotic $\mathrm{N}_{2}$ fixation, lowering the fertilizer $\mathrm{N}$ requirements and fossil energy use of farming systems, and thus reducing the net release of greenhouse gases into the atmosphere [4]. To obtain these ecosystem services, farming systems must increase crop diversity with more legumes cultivated both in quantity and in number of legume species cultivated. Moreover, crop diversity is linked to the capacity of markets to use a variety of crops for feed and food $[5,6]$. For soya, huge markets exist, whereas strong innovation is still needed for pulses to break out of the lock-in they face compared to global major crops [7-9]. Even though today legumes are increasingly promoted for human protein intake, enabling a reduction in animal-based consumption, pulses have had difficulties to develop in those markets [7].

Within the same crop family_-grain-legumes-pulses and soya have developed very differently since the 1960s. Soya is the main worldwide protein crop grown mainly for feed use (with soya oil increasingly becoming a byproduct). Nowadays, the soya crop amounts to more than 300 million metric tons, while other main grain-legumes such as pulses (pea, lentils, lupins, faba beans, chickpeas, etc.) account for less than 100 million metric tons (Appendix A, Table A1). At global scale, pulse production has gained little ground, whether for food or for feed. Thus, the United Nations launched an International Year of Pulses (IYP) in 2016 to raise awareness about the considerable contributions pulses can make to the sustainability transition of agrofood systems, and to favor their development compared to major crops such as soya [10,11].

To contribute to such new trajectories for grain-legumes, there is a consensus in Science and Technology Studies (STS) that increasing scientific research is essential. Science provides a stock of knowledge for driving new developments and innovation [12-14]. Hence, the main objective of our study is to assess the shares of research activity among the grain-legumes crops in order to evaluate whether research on grain-legumes is itself locked around soya or provides knowledge on a variety of species. Measuring science has been an ambitious challenge for many authors in STS since the seminal works of the 1980s [14]. Bibliometric and scientometric methods are now well-established for analyzing scientific advancement and for orientating research policy [15-20]. The considerable development of scientific platforms [21], combined with algorithmic advances for performing bibliometric analyses, has furthered interest in exploring the dynamics of scientific knowledge [19,22]. Through knowledge and scientific analysis, gaps and opportunities in science can be identified and addressed to meet society's needs for innovation. For sustainability transition studies, bibliometric analysis enables us to better understand the state of knowledge of the current sociotechnical regime that needs to be changed, particularly in sectors with strong path-dependency. Consequently, the number of bibliometric analyses has been growing for a variety of fields: in electronics [23], on scientific parks and the links to open innovation [24], or in pharmaceuticals [17]. However, few have been done in agriculture (e.g., on agroecology [25]), even though there are key sustainability issues challenging research. 
To evaluate the respective shares of grain-legume species in the sciences, we used the Web of Science (WoS) collection to retrieve the scholarly publications reflecting research activity recognized by peers. As advanced by STS, and more specifically by scientometrics studies [19], these research papers remain the highest quality variable to reflect research activity on a given topic. Even though GS (Google Scholar) is growing and presented as alternative, the metadata offered by GS are still very limited, reducing the practical suitability of this source for large-scale citation analyses. In addition, GS includes around $20-50 \%$ of other type of research documents (depending on the scientific fields), such as $\mathrm{PhD}$ dissertations, scientific reports, and non-peer-reviewed papers that create bias in comparing research advancement from more qualitative types of research documents [26]. Moreover, language harmonization rules are required to collect data on GS. Therefore, although perhaps not a perfect resource to reflect all the scientific knowledge stock, we chose a traditional bibliometric platform, as the WoS as better for providing more a relevant overview of peer-reviewed research activity (i.e., the scholarly documents such as articles in peer-reviewed journals, books and book chapters), $97 \%$ of which were written in English on the WoS. An alternative bibliometric platform is Scopus, but we chose WoS thanks to our institution access; and Scopus use will generate additional computing methods to extract large collection as we did on the WoS, without adding so much other records as WoS and Scopus present high overlap level [26].

We chose to focus on temperate climate species; that is, the grain-legume species grown in most Western countries; but many of them are also important grain-legumes for semi-arid or tropical areas. In analyzing the scholarly publications on grain-legumes, we wanted to assess the relative occurrences of several grain-legume species and which countries had been the most involved in this research. We performed this analysis for research over the last four decades (between 1980 and 2018), by considering ten themes (i.e., scientific fields) of interest in agrofood system research and identified by experts: Genetics, Agronomy, Ecophysiology, Biotic-stress, Feeding, Processing, Nutrition, Allergy, AcсертAвILITY, and Socioeconomics. No review of the literature to date has managed to tackle so many themes of interest together for both agricultural and food sciences, whatever the crop species considered.

This original and ambitious literature review involved 26 scientific experts on legumes, coupled with database and scientometrics experts to create relevant search queries on the WoS and appropriate software to process and analyze the resulting bibliographic records. Our findings are based on a core corpus totaling 107,823 scientific publications (i.e., records) retrieved by thematic search queries addressing the title, abstract, and authors' keywords. Since soya is a major crop used for oil unlike most other grain-legumes, we excluded records referring to the subject of "soya oil", in order to have more relevant comparisons in the corpus created. Our results show that soya is mentioned in $43 \%$ of the records, groundnut in nearly $10 \%$ and all other pulses combined in $47 \%$. The analyses revealed a strong imbalance within grain-legume species research, with soya dominant over all other grain-legume species; and if "soya oil" had been included in keyword searches, this percentage would be even greater. This trend has grown even stronger in recent years. We also observed that the breakdown of themes researched were not the same for soya and pulses. Processing and Nutrition were much more common themes of research for soya than for pulses. For pulses, research mainly focused on "upstream" themes linked to Genetics or Ecophysiology. This imbalance questions the capacity of research to develop knowledge that would enable more food outlets for pulses, as expected by the United Nations during the IYP.

\section{Materials and Methods}

\subsection{Overview of the Methodology Adopted}

This study was based on a bibliometric dataset retrieved from the Web of Science (WoS) a product of Clarivate Analytics. As mentioned in Section 1, Scopus is the other prominent bibliographic database, which presents a high overlap with the WoS: see [26] for a comparison of these databases stressing their limitations and advantages to conduct large-scale literature analyses. The WoS is one of the most used 
bibliometric resources in the world. It provides access to article records from more than 30,000 journals and books in various fields of science. The WoS "Core Collection" includes about 70 million records [27].

For the present study, we worked with several scientific experts to identify domain-specific keywords and retrieve the associated scientific publications (records). First, we identified keywords covering most of the cultivated grain-legume species in Western countries (SPECIEs query). Second, we determined 10 domain-specific themes covering the main research issues on grain-legumes (e.g., Allergy). Then, search queries on the WoS were designed to delineate the species and each theme (Table 1), leading to 10 thematic corpora on grain-legumes. Finally, these 10 corpora were merged into a single corpus called Fusion. All search queries and the associated publication records are available as open data from the https://data.inra.fr repository (Appendix A, Table A2).

In this article, a "corpus" is a set of records retrieved from the WoS and a "record" refers to the metadata of a scholarly document (e.g., the type of publication, such as "article", "book chapter"; the authors; etc.). Designing these queries was an iterative process requiring a combination of skills:

- $\quad$ Theme experts

We identified leading scientists in several fields (Table 1) who helped to delineate search queries for 10 key themes and to check the validity of the records retrieved. (Delineation of scientific fields or subject areas is a question under much discussion in scientometrics. Bibliometric databases developed their own classification reflecting the scope of journals. As such classification were not directly suitable to break down agricultural and food research activity in several fields on which to build our search queries, we relied on experts' judgement to define 10 themes of main interest covering the research on grain-legumes. We used the term of "theme" as a synonym of "subject area". See [20] to go further on this question of delineation of scientific fields).

- Scientometricians

We collaborated with scientists who specialize in the quantitative study of science and database management systems to create an online platform giving access to the corpora collected. This platform was used to then incrementally refine search queries to build the corpora. Since the number of records to collect from the WoS $(100 \mathrm{k})$ exceeded the amount of records one can extract from the web interface (limited to $5 \mathrm{k}$ ), we resorted to a Web of Science Data Integration feature. Data collection was then performed with an in-house program using the Web of Science API Expanded.

Table 1. Thematic corpora investigated by experts.

\begin{tabular}{|c|c|c|}
\hline $\begin{array}{l}\text { Theme and Underlying } \\
\text { Corpus Name }\end{array}$ & Description of the Theme & $\begin{array}{l}\text { Number of Scientific } \\
\text { Experts Involved }\end{array}$ \\
\hline Species & $\begin{array}{l}\text { Names used to designate the various main grain-legume species } \\
\text { and varieties cultivated in temperate climates }\end{array}$ & 2 \\
\hline Genetics & Varieties, genes, breeding methods and objectives & 2 \\
\hline Agronomy & Ways to grow legume crops and provided services & 2 \\
\hline ECOPHYSIOLOGY & Plant physiology in relation to its abiotic environment & 2 \\
\hline BioticStress & Weeds, diseases, and pests' life traits and control in crops & 2 \\
\hline FeEding & Feeding practices, animal nutrition & 2 \\
\hline Processing & $\begin{array}{l}\text { Transformation and main types of food products excluding } \\
\text { non-food uses }\end{array}$ & 4 \\
\hline Nutrition & Nutrition subjects for humans including health & 4 \\
\hline Allergy & Concerns on allergy linked to the use of legumes in food & 2 \\
\hline ACCEPTABILITY & Sensorial and organoleptic analysis for consumer acceptance & 2 \\
\hline Socioeconomics & Any subject of interest using socio-economic approaches & 2 \\
\hline
\end{tabular}

Regarding the 10 domain-specific themes selected, we adopted a broad-spectrum approach covering the end-to-end workflow of grain-legume research from production to consumers. A growing concern in Western countries is to increase legume consumption [28]; therefore, we made sure to cover allergy and consumer acceptance subjects. We also designed a query capturing the main socioeconomic 
research theme on grain-legumes (e.g., funding of work on breeding activities, farmers' production choices, feed practices and business, consumer behaviors, and market functioning, policies). This query led to the corpus called Socionconomics, a research theme complementary to the others on life sciences and engineering.

Performing the statistics at the meta-level required merging the 10 thematic corpora on grain-legumes into a single corpus called Fusion. We merged all records from the underlying corpora, removing duplicates that we identified thanks to the unique identifier provided for each record in the WoS (UT code). As a result, a record in Fusion appeared only once, even if it appeared in multiple underlying corpora.

\subsection{Designing Search Queries on the WoS: Main Principles}

This section introduces the main principles we followed to design the search queries (Table A2) (for the syntax rules of search queries, see the Web of Science Core Collection Help: http://images. webofknowledge.com/WOKRS5251R3/help/WOS/hp_search.html).

\subsubsection{Documents Type}

The search was restricted to the main types of scientific literature documents, namely: article, book, book chapter, and review. This translated into the query: DT = "Article" OR "Book" OR "Book Chapter" OR "Review").

\subsubsection{Time Range}

We selected the period 1980-2018 (PY = "1980-2018”) to observe long-term dynamics. This timeframe encompasses document records of variable completeness: abstracts were available only starting in 1990. We expected an increase in the volume per year to raise around 1990 because search queries would match more records in both the titles and abstracts.

\subsubsection{Indexing as a Post-Processing Step to Cleanse the WoS Results}

WoS queries were issued with the standard TS operator, meaning Topic Search. TS results collect records of the database that match the user's query on the following criteria: title, abstract, author keywords, and KeyWords Plus. KeyWords Plus are additional terms automatically generated by the WoS and attached to the records. Terms appearing more than once in the titles of the cited references in a record (i.e., in its bibliography section) are called KeyWords Plus [29]. For instance, a search like TS = "protein AND pea" matches documents whose title, abstract or author's keywords contain the term "protein" but not "pea", because the term "pea" occurred only in the bibliography of the document retrieved ("pea" being a KeyWords Plus here) (see, for instance, query UT = "WOS:000226807600008" AND TS = ("protein" AND "pea") yielding one journal paper on rice mutants, whose abstract contains "protein" but not "pea"). This example stresses that the records retrieved from the WoS might contain records that were not of direct interest. In our point of view, a document of direct interest (to build a core corpus) must contain both terms in the main contents provided only by the authors: title, abstract, and author's keywords.

To circumvent the biases introduced by KeyWords Plus, we designed an indexing algorithm that cleaned the WoS results by filtering out non-direct interest documents. Each remaining document had to match our criteria: only author-specified contents should be matched with the query. We applied this indexing algorithm to the 10 thematic queries.

\subsubsection{Interactive Browsing of the Bibliographic Corpora}

To ease team work with the thematic experts, we designed an online interactive bibliometric platform called SCIM, enabling them to explore the resulting records. The thematic corpora are shown with a clear distinction between direct interest vs. non-direct interest documents. Skimming 
through the latter allowed experts to check that those eliminated records were clearly out of scope (i.e., validation of the aforementioned indexing step). In addition, using descriptive statistics, experts were instructed to check the relevance of the records included. They checked the most frequent terms, journals, and Web of Science categories (wcs in the WoS parlance (http://images.webofknowledge.com/ WOKRS5251R3/help/WOS/hp_subject_category_terms_tasca.html)) associated with the records of the direct interest documents.

\subsubsection{Iterative Design and Validation of the Search Queries}

Each thematic search query was stabilized with an iterative validation process involving the experts at each iteration. One iteration involves the following tasks applied to each thematic corpus:

- Checking of a random sample from the thematic corpus.

Each expert was asked to examine the records from a random selection of the 300 documents published during the last three years and present in the thematic corpus he/she was responsible for. Documents considered irrelevant were analyzed to deduce the changes that needed to be made on the search query in order not to retrieve these in the next iteration. Conversely, experts were also asked to identify those aspects of the theme that were not caught by the query. In particular, experts expected the leading authors or topics to appear (the three last years corresponding to the current state of the art); they used this information to adjust search queries when necessary. Overall, the search operator $t 1$ NEAR/ $10 t 2$ (i.e., term $t 1$ must be within 10 words away from term t2) proved the most efficient for identifying relevant thematic corpora. In our case, $t 1$ were names of the species studied while $t 2$ were terms related to the considered theme. This first task iterated until the percentage of irrelevant documents was less than $20 \%$ of the random sample.

- Checking of the entire thematic corpus.

This second task relied on descriptive statistics. For each thematic corpus, experts were instructed to assess the relevance of the most frequent:

terms in the title, abstract, authors' keywords of the records; and

WoS categories (wCs) reflecting the scope of the journal or the book that the WoS attributes to each record of the bibliographic database.

Irrelevant terms or wcs with high frequencies relative to the thematic corpora were identified and used to adapt, once again, the search query. In particular, this led the experts to specify excluding conditions (see below).

During this phase, the experts of closely related scientific themes (for instance, between Ecophysiology and Agronomy, or between Nutrition and Processing) collaborated to better delineate each theme. Several meetings with all experts led to adaptations of the queries between themes. This ensured a reduced asymmetry of knowledge between the scientific experts for each theme, which helped to better delineate the search queries.

\subsubsection{Excluding Conditions}

Queries feature excluding conditions on some keywords or wcs, for specific themes or for all of them.

- For instance, in the Processing query, the "germination" keyword is ambiguous, as it relates to either a food subject or an agronomic subject (as regards the germination step of seeds in the soil concerning more the Ecophysiology corpus). As "germination" was a keyword that we need to keep for the Processing query, we excluded the wCs of the Processing corpus not related to "Nutrition Dietetics" and "Food Science Technology".

- For all queries: 
The terms "coffee" and "cacao" where excluded because they also appear in the underlying paper under the generic term "bean".

- The phrase "soya oil" was excluded due to a twofold rationale. First, it is over-represented in the literature on soya. Second, comparing soya and pulses requires selecting common features of legume interests, such as the increasing interest in plant-based protein development for food instead for oil [28].

The phrase "biodiesel" and "biofuel" as products linked to oil fraction was excluded. In general, non-food uses are beyond the scope of this study.

Finally, all of these issues meant that conducting a bibliometric study requires careful, in-depth, and iterative expert coordination for performing the many checks and refining the search strategy. Compared to the delineation strategy established for this Fusion corpus (Figure 1), other delineation strategies were also tested and are reported in Appendix B. Those alternative delineation strategies resulted in less relevant corpora than with the delineation strategy of Figure 1 (see Table A5 for instance).

Delineation strategy

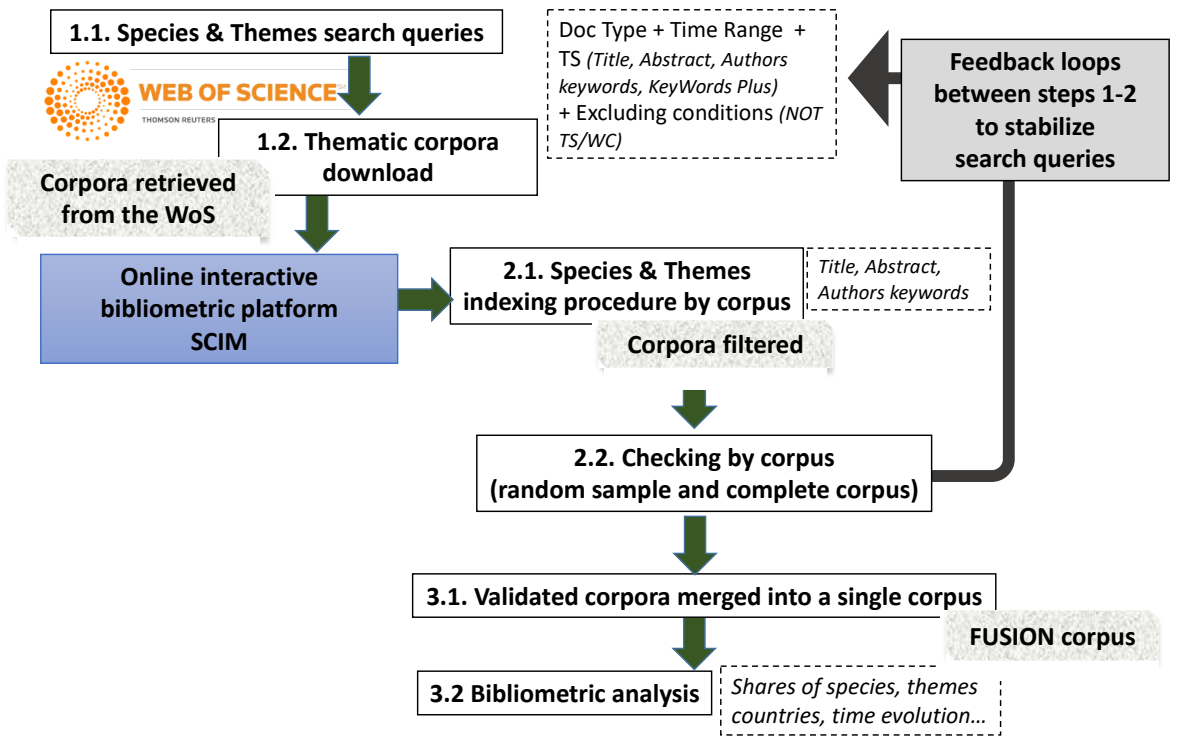

Figure 1. Main steps to build the bibliometric dataset: the delineation strategy.

This figure summarizes the main steps followed to build the thematic corpora. First, queries were submitted to the Web of Science to collect bibliographic records for each theme (Steps 1.1 and 1.2). Second, the indexing phase eliminated the records retrieved because of KeyWords Plus only (Step 2.1). Then, for each theme, surviving records were checked by experts: first, on a random sample, and, second, for the complete corpus (Step 2.2). Third, the experts relied on descriptive statistics to identify the remaining irrelevant documents; they modified the query accordingly and re-ran the whole process. In this way, queries were progressively refined. Finally, the 10 thematic corpora validated by experts were merged to form a single corpus of unique records called Fusion (Step 3.1), on which the bibliometric analysis relied (Step 3.2).

\subsection{Focus on the Design of the Species WoS Query}

The 10 thematic search queries were combined with a query targeting the names of grain-legume species. Hence, delineating the various terms referring to grain-legumes was a crucial part of our bibliometric study. This was a challenging task as different names are used in different scientific fields. Either the scientific name (generally the Latin name) or various, country-specific, common names were 
used. The expertise of two senior researchers internationally recognized on those crops, combined with the consulting of websites dedicated to data collection on plants (Table 2) and books on plant taxonomy (e.g., [30]) enabled us to list more than 80 various names that we grouped into 19 main grain-legumes species (Table 3). Only main pulses, soya, and some species from the genera Lathyrus and Vicia cultivated in temperate climates (mainly of Western countries and the Mediterranean basin) were considered here. All these species belong to the family of grain-legumes. Among them, according to the United Nations, the grain-legumes not used for oil extraction are commonly called pulses, excluding soya and groundnut for their dual richness in oil and protein. Appendix $C$ gives a brief history of grain-legumes and reveals that while pulses were common crops for centuries, interest in them has dramatically decreased in recent decades compared to soya.

Table 2. Main sources consulted to check the various terms used for grain-legumes species.

\begin{tabular}{|c|c|}
\hline Name & Website \\
\hline $\begin{array}{c}\text { Tela Botanica, the French-speaking network of botanists, } \\
\text { presenting Latin name of species }\end{array}$ & https://www.tela-botanica.org/ \\
\hline $\begin{array}{l}\text { Feedipedia, describing all the resources used for feed in the } \\
\text { world, and among them legumes }\end{array}$ & https://www.feedipedia.org/ \\
\hline $\begin{array}{l}\text { Atlas managed by the CGIAR-Research Program on } \\
\text { Dryland Cereals and Legumes Agri-Food Systems (DCL) }\end{array}$ & http://www.eatlasdcl.cgiar.org \\
\hline A personal website created by a renowned retired botanist. & https://www.cropsreview.com/grain-legumes.html \\
\hline Inventory of food resources and constituents & http://foodb.ca \\
\hline
\end{tabular}

Table 3 presents all the species terms included in the SPECIEs search query, classified according to a single species identifier and a generic one. For instance, we gathered under the identifier "soya" all occurrences of various terms referring to soya by using wildcards such as in the following list: glycine max, soja, soya $\$$, soy $\$$, sojabean\$, soybean\$, and soyabean\$. These species identifiers served for the indexing step (explained in Step 2.3) and the exploratory statistics.

As for the thematic search queries, wildcards were used to catch various forms of a term: for instance, being written in plural or singular or with varying country-dependent orthotypography (e.g., soya vs. soja and faba vs. fava bean). The asterisk $\left({ }^{*}\right)$ represents any group of characters (including no character), the dollar sign (\$) represents zero or one character. The phrases (expressions composed of several terms), such as "chick pea", were surrounded with quotation marks in the search queries applied on the WoS.

Some generic terms (such as legumes and leguminous) were also considered, but they were only added for the Socionconomics search query. For the other themes, using these generic terms retrieved too many irrelevant records: that is, records mentioning legumes without dealing specifically with grain-legumes. One explanation for this relates to how scientists phrase their papers: some (especially life sciences) usually work on a specific legume, while others (especially social sciences) tend to consider legumes in a more comprehensive approach. 
Table 3. Species identifier and species expressions used in the species search query.

\begin{tabular}{|c|c|}
\hline $\begin{array}{l}\text { Species Identifier (Genus } \\
\text { or Common Name) }\end{array}$ & All Species or Common Name Terms Included in the Search Query \\
\hline Adzuki & phaseolus angularis, vigna angularis, red mung $\$$, red bean $\$$, red mungbean $\$$, adzuki $\$$, azuki $\$$ \\
\hline Bambara Bean & vigna subterranean *, bambara bean\$ \\
\hline Bean & $\begin{array}{l}\text { phaseolus coccineus, phaseolus vulgaris, phaseolus lunatus, phaseolus spp, common bean\$, } \\
\text { common field bean\$, common fieldbean\$, runner bean\$, runnerbean\$, lima bean\$, common } \\
\text { bean\$, kidney bean\$, pinto bean\$, vigna aconitifolia, moth bean\$, vigna umbellata, rice bean\$ }\end{array}$ \\
\hline Chickpea & cicer arietinum, chickpea $\$$, chick pea $\$$ \\
\hline Cowpea & $\begin{array}{l}\text { vigna unguiculata, cowpea } \$ \text {, cow pea, cow peas, blackeyed pea, blackeyed peas, black-eye pea, } \\
\text { black-eye peas, blackeyed bean } \$ \text {, catjan } \$ \text {, long bean } \$\end{array}$ \\
\hline Faba bean & $\begin{array}{l}\text { vicia faba, fava bean\$, faba bean\$, broadbean\$, broad bean\$, horse bean } \$ \text {, horsebean\$, } \\
\text { fababean\$, field bean\$, fieldbean\$ }\end{array}$ \\
\hline Fenugreek & trigonella foenum grecum, trigonella foenum graecum, fenugreek $\$$, fenugrec $\$$, fenu grec $\$$ \\
\hline Lathyrus & $\begin{array}{l}\text { lathyrus sativus, lathyrus sativa, lathyrus ochrus, lathyrus cicera, grass pea } \$ \text {, red pea } \$ \text {, cyprus } \\
\text { vetch } \$ \text {, vetchling } \$ \text {, gesse } \$\end{array}$ \\
\hline Gram bean & vigna mungo, gram bean $\$$, black bean\$, black lentil\$, black gram, blackgram $\$$ \\
\hline Groundnut & arachis hypogea, arachis hypogaea, groundnut\$, peanut\$ \\
\hline Lablab & lablab purpureus, hyacinth bean\$, lablab bean\$, lablab\$ \\
\hline Lentil & lens culinaris, lentil\$ \\
\hline Lupin & lupinus albus, lupinus angustifolius, lupinus luteus, lupinus mutabilis, lupin\$ \\
\hline Mungbean & $\begin{array}{l}\text { vigna radiata, vigna mungo, mungbean } \$ \text {, mung bean } \$ \text {, moong bean } \$ \text {, mungo bean } \$ \text {, green } \\
\text { gram } \$ \text {, golden gram } \$ \text {, maash } \$ \text {, moong sanskrit } \$\end{array}$ \\
\hline Pea & pisum sativum, pea, peas \\
\hline Pigeon Pea & cajanus cajan, pigeon pea, pigeon peas, pigeonpea\$ \\
\hline Soya & glycine max, soja, soya $\$$, soy $\$$, sojabean $\$$, soybean\$, soyabean\$ \\
\hline Vicia & vetch\$, vetche\$, vicia sativa, vicia villosa, vicia ervilia, ervil\$, vicia narbonensis, narbon bean\$ \\
\hline Winged bean & psophocarpus tetragonolobus, winged bean\$, asparagus pea\$, goabean\$, goa bean\$ \\
\hline Generic & leguminous, ${ }^{*}$ legume, ${ }^{*}$ legumes, pulse, pulses \\
\hline
\end{tabular}

Note: $\$$ (respectively, ${ }^{*}$ ) is a wildcard replacing zero or one character (respectively, no character at all or a group of characters). For instance, "*legumes" matches "grain-legumes" or "dried-legumes".

\section{Results and Discussion}

Bibliometric analysis allowed us to mine this dataset and infer new knowledge on grain-legume research at the global scale. The main purpose of this paper is to shed light on the share of species in these corpora, reflecting the research activity on grain-legumes. Thus, we calculated the percentage of records on each species within the corpora, longitudinally and at different levels of analysis, according to species, themes, and countries, especially by comparing soya and pulse frequencies. Then, we discuss the implication of these results as regards avenues for future research and policies regarding the question of crop diversity.

\subsection{Proportions of Grain-Legume Species in the Scientific Literature}

For this subsection, we consider five groups of grain-legume species when reporting our results:

- $\mathrm{G} 1$ is for Soya.

- Pulses divided into three groups:

- G2 groups "PFL" including Pea, Fababean, and Lupin species. This group is the European classification of the main protein-rich crops among pulses.

- G3 groups "Other pulses" for the remaining pulses but excluding "Lathyrus and Vicia"

- G4 groups Lathyrus and Vicia species together as the number of records related to those species are very low and currently the least used.

- $\quad$ G5 is for Groundnut (not considered as a pulse because of its oil richness). 
Table 4 present the shares of the five groups of grain-legume species captured in the Fusion corpus: G1, G2, and G3 appear in Table 4a, while G4 and G5 appear in Table 4b.

We also distinguished the counts of species co-occurring with generic terms. Indeed, in the indexing procedure (see Section 2), we indexed the records with generic names of species such as "legumes" or "pulses", in order to appreciate how researchers broaden their studies by referring also to the family group of legumes. Therefore, some figures in this subsection present specific counts of the co-occurrence of a generic term with a specific species' name in records. In addition, we report the average annual growth rate of records in the Fusion corpus.

Table 4. (a) Number and percentage of records in the Fusion corpus related exclusively to soya or pulses, broken down by time periods. (b) Number and percentage of records in the Fusion corpus related exclusively to groundnut, Lathyrus or Vicia, broken down by time periods.

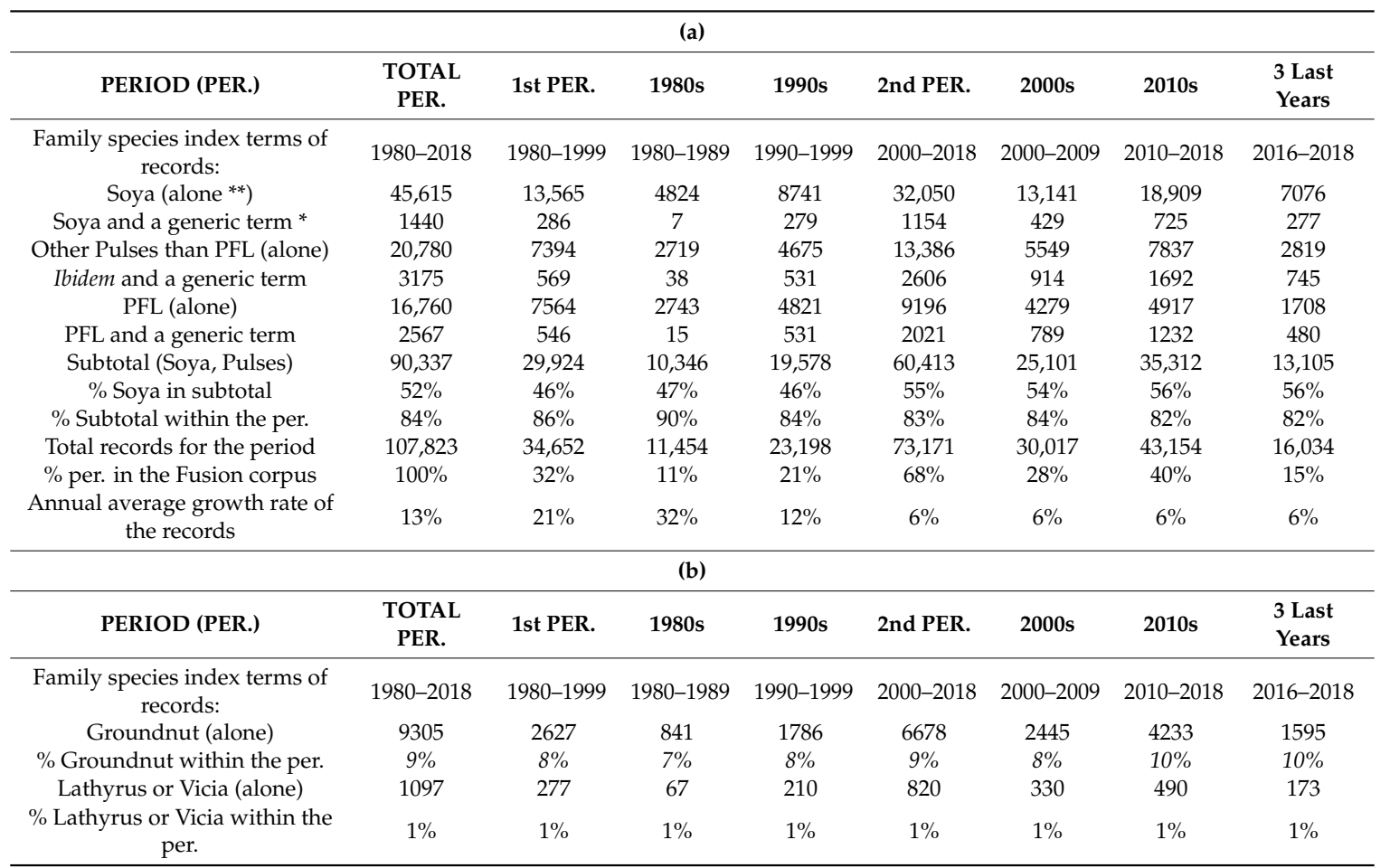

(a) Note: Each row in the table is exclusive of that group. PFL: pea, faba bean, or lupin. ${ }^{*}$ For instance, this row shows the number of records containing only a generic term (a generic term such as legumes) AND a term linked to soya in the Title, Abstract or Authors' keywords. ** The various combinations of species index (associating pulses, soya or groundnut in records) are not included here. For instance, over the entire period, we counted 838 records co-indexed with groundnut and soya; 298 records co-indexed with Lathyrus-Vicia and PFL, etc. These various co-indexations records over the entire period represent $6 \%$ of the Fusion corpus. (b) Note: Each row in the table is exclusive of that group.

3.1.1. The Number of Grain-Legume Publications Grew at the Same Rate as All Records in the WoS Core Collection

First, concerning changes in the corpus size over time, we observed that, even though today there is greater awareness of legumes, the growth of scientific publications on grain-legumes is similar to that within the whole WoS Core Collection; the annual growth rate in scholarly peer-reviewed English-language journals of the WoS increased 5-6\% in recent decades [27] (p. 25). The specific higher rate in the years 1980 and 1990 is due to the increase in research activity and publications observed in the entire WoS Core collection (due also to the WoS index rule changes since 1990 including both abstracts and keywords), and not to a special interest in legumes. Therefore, these figures firstly show that there has been no particular increase in legumes research, even after the United Nations' communication about the benefits of pulses for sustainability in the 1980s [31] and more recently in the 2010s (IYP in 2016). Nevertheless, researchers are aware that most publications observed in a given 
year are the results of research conducted over the three or more previous years. Therefore, measuring any impact from IYP 2016 on the number of publications can take at least 10 years, given that, before an increase in research activity, public and private decisions must be taken to increase funding for that research.

Overall, as in the entire Core Collection, the second period (post-2000s) represents nearly two-thirds of the corpus, with a net increase in research activity (as in the WoS Core collection) since 2010: the 2010-2018 period accounts for $40 \%$ of the records in the Fusion corpus. This point is important to stress: as there has been a rapid and strong increase in scientific knowledge, it is crucial to adopt tools to analyze the ways that new knowledge is created. We need to assess the risk of over-investigating some themes or species and under-investigating others.

3.1.2. Generic Terms Referring to Legume or Pulse Family Are More Used with Pulse Species than with Soya Species

Second, concerning the frequency of generic term co-occurrence with species indexes, we observed different tendencies for soya and pulses. Table $4 \mathrm{a}$ shows that pulse species were more frequently co-indexed with a generic term than was soya. For instance, for the most recent period (2010-2018), $19 \%$ of pulse records are co-indexed with a generic term compared to $4 \%$ for soya records. Soya is a dominant crop having developed its own identity, making it distinct from other legumes. In other words, it seems that the identity of belonging to a larger family such as legumes is stronger for pulses species than for soya. It reflects also the fact that research studies focus on one species and rarely relate to the broader context of legumes or pulses.

In addition, the results show a low rate of co-indexation between species (6\%) (Table 5 and Figure 2). This means that the links between species are rarely stressed by the authors. In particular, only $2 \%$ of records were co-indexed both with soya and a pulse species. Thus, researchers rarely considered two (or more) species when investigating an issue, or, at least, the extension or impacts of the results for other species of the same family were rarely mentioned. This finding fundamentally questions the diffusion of knowledge between species and calls for future research using semantic networks to analyze which concepts (i.e., knowledge) are used when establishing connections between species. Moreover, here we considered only the titles, abstracts and keywords; it is possible that the main text of the article mentioned such impacts for species other than the main one under investigation. However, titles and abstracts express the core message of an article, and considering application of results for other species does not seem to be part of this core message for most research work.

\subsubsection{Soya Strongly Dominates within Grain-Legume Publications}

Third, these frequencies show the predominance of soya among grain-legumes (Figure 2). It is important to note that this soya predominance is underestimated, as all records referring to "soya oil" were eliminated. When such a similar exclusion is performed on groundnut (i.e., excluding "oil" theme), its ranking is lower: among 11, 612 records indexed with "groundnut", 50\% refer to oil thematic. Within the subtotal formed by soya and pulse groups (the two main species families of current interest in developed countries, notably for increasing plant-based protein), soya accounts for more than half of all records. This tendency has grown even stronger in recent years, with soya reaching $56 \%$ of the records. 
Table 5. Number and percentage of the various grain-legume species quoted in Fusion corpus.

\begin{tabular}{ccc}
\hline Species Index & Number of Records & Share of Species Index \\
\hline Soya & 51,395 & $42.6 \%$ \\
Pea & 14,175 & $11.7 \%$ \\
Groundnut & 11,612 & $9.6 \%$ \\
Bean & 8976 & $7.4 \%$ \\
Cowpea & 5954 & $4.9 \%$ \\
Chickpea & 5373 & $4.5 \%$ \\
Faba bean & 4640 & $3.8 \%$ \\
Mungbean & 3785 & $3.1 \%$ \\
Lupin & 3420 & $2.8 \%$ \\
Lentil & 2724 & $2.3 \%$ \\
Pigeon Pea & 2302 & $1.9 \%$ \\
Vicia & 2036 & $1.7 \%$ \\
Gram bean & 1466 & $1.2 \%$ \\
Adzuki & 771 & $0.6 \%$ \\
Fenugreek & 762 & $0.6 \%$ \\
Lathyrus & 491 & $0.4 \%$ \\
Lablab & 390 & $0.3 \%$ \\
Winged bean & 232 & $0.2 \%$ \\
Bambara Bean & 173 & $0.1 \%$ \\
Total species quotes & 120,677 & $100 \%$ \\
\hline $\mathrm{Nb}$ of records indexed with only one species (\%) & & \\
$\mathrm{Nb}$ of records co-indexed with several species (\%) & & $700,739(94 \%)$ \\
$\mathrm{Nb}$ of records in FUSION corpus & & $107,823)$ \\
\hline
\end{tabular}

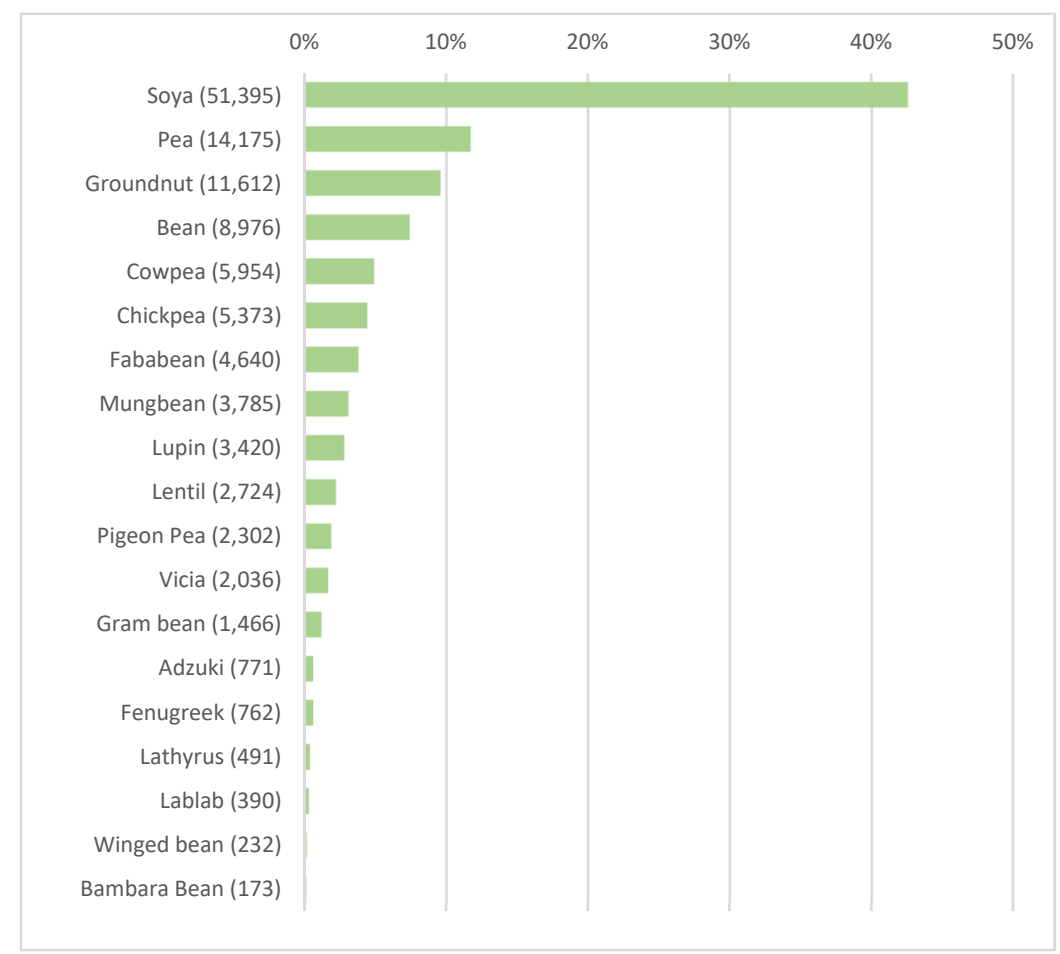

Figure 2. Species distribution quotes in Fusion corpus.

Fourth, when looking for the distribution of all the grain-legume species under study (Table 5), the predominance of soya is more accurate as the second main species, pea, accounts for nearly $12 \%$ of the mentions, compared to nearly $43 \%$ for soya. Among pulses, the five most mentioned species were, respectively: pea, bean, cowpea, chickpea, and faba bean. 
As explained in Appendix B, we created alternative bibliometric corpora (Species1, Species2, Species3). Although in these alternative corpora the themes are less well delineated, it was worthwhile to check whether the species frequencies were similar, since, with the SPECIEs3 and Fusion corpora, nearly one-third of the records were not common to both. Finally, we observed the same statistics for these other corpora and the percentage of species was similar (Table A6). Overall, soya accounts for more than half of the scientific publications within the soya and pulse records, with the share of soya increasing in recent years. We also observed in these alternative corpora that soya and pulses represented around $90 \%$ of the records on grain-legumes.

\subsubsection{Changes in the Mentions of Species over Time}

Figures 3 and 4 present the longitudinal evolution of the ten most mentioned species. Soya is the species with the highest number of publications: 45,615 records co-indexed with soya (Table 4a). The increase in records indexed with groundnut, chickpea, lentil, or mungbean was greater in recent years compared to other pulse species.

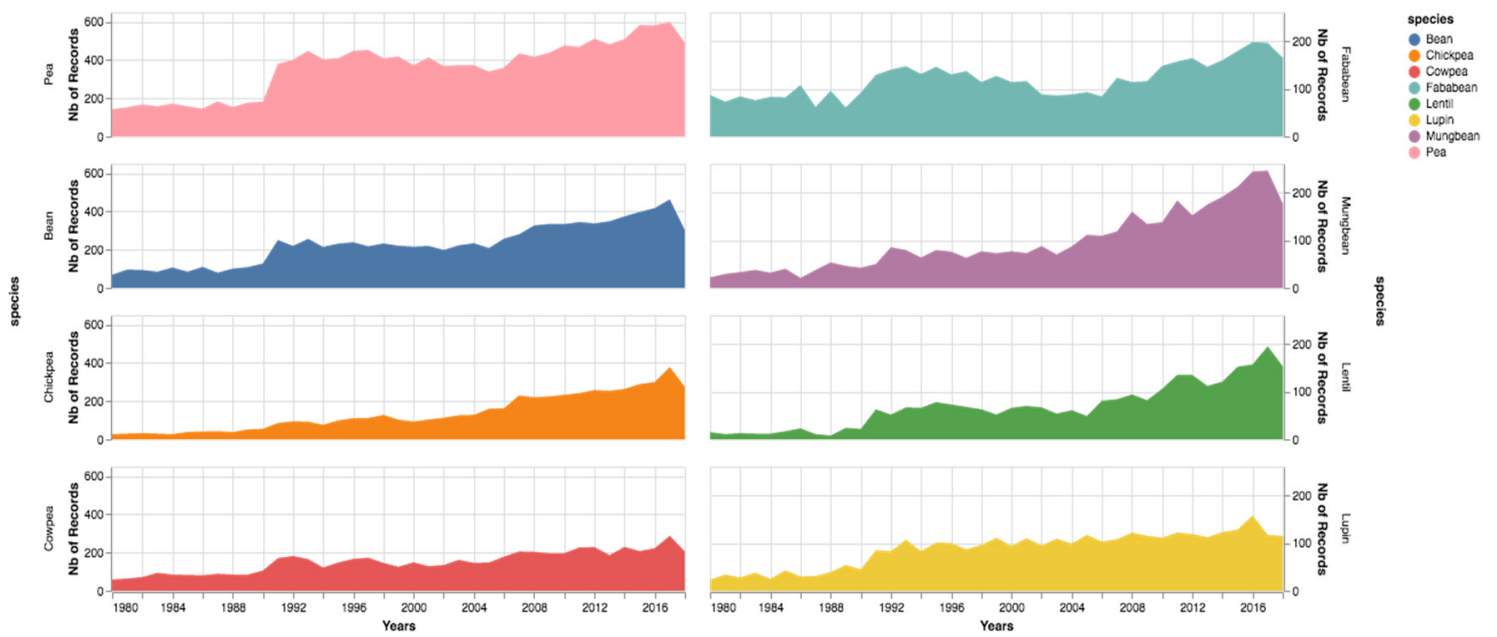

Figure 3. Longitudinal evolution of main pulses species quoted in Fusion corpus.
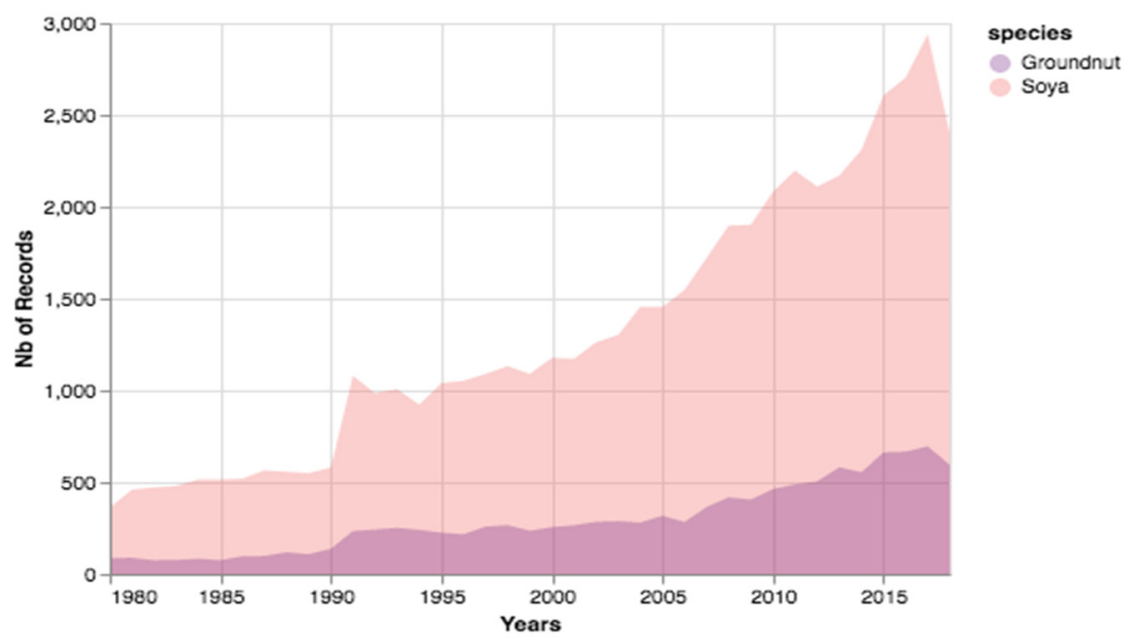

Figure 4. Longitudinal evolution of Soya and Groundnut species quoted in the Fusion corpus.

\subsection{Percentage of Grain-Legume Species in Literature across Countries}

The metadata of most records retrieved from the WoS identified the countries of the authors. We studied the share of soya and pulses research by country. Figures 5 and 6 and Table 6 report a proportional count for international collaboration records (that is associating several countries): 
each country accounts for $1 / n$ where $n$ is the number of countries associated for the record. As most international collaborations involved few countries, those publishing the most on grain-legumes, this rule avoids overcounting them as when one uses full counting (i.e., 1 point to each country). We observed that with or without proportional counting, the ranking of countries did not change (Figure 5a,b). We also created a specific geographical index of the current 28 European Union countries (whatever the period considered), while computing the count for individual European countries. For the following data, we considered only the records indexed either with soya or with pulses and for which authors' countries were identified (around 15,000 records in the Fusion corpus did not have this information in the WoS; these are mostly papers with multiple authors and only one reprint address, see UT $=$ WOS:A1997XJ61100010, for instance).

\subsubsection{The Ranking of Countries Was Rather Stable over Time, with China, Brazil, and India Rising}

First, Figures 5 and 6 show that the ranking of countries was different for soya and pulses, but quite stable over time. Considering both soya and pulses, the two first publishing geographical areas are the USA and the EU28, considering either the whole period or the current decade. The USA and the EU28 account for more than half of the records in the previous period, but less than one-third in the current decade (Table 6). More recently, China has been rising and currently represents 13\% of the records in the current decade, followed by India, Brazil, Japan, Canada, and Australia. These seven countries and the EU28 account for two-thirds of the records on soya and pulses over the current decade (versus $84 \%$ in the previous period). This reveals a progression of other countries in legume research, such as South Korea and Argentina.

\subsubsection{The Percentage of Soya and Pulses Records per Country Is Quite Stable over Time}

Second, a clear opposition appears with some countries that focus more on pulses than on soya. This is particularly the case for the EU28 and India (and for Australia but with fewer records) and for the countries geographically close to them. Over the whole period, the EU28 accounted for more than a quarter of the studies on pulses, but less in the current decade because of India's increase. For instance, while the EU28 has two times fewer records in the current decade than during the previous period, it is the opposite for India which has doubled records in the current decade (Table 6). Canada is the only country publishing as much on soya as on pulses, whatever the period. Other countries work more on soya, increasing the imbalance with pulses: this is particularly the case for China which currently publishes nearly four times more on soya than on pulses, with the USA three times more, and Brazil twice more.

Among the 20 most publishing countries, there are six European countries in the current decade: Spain, Germany, France, Italy, England, and Poland. They also represent two-thirds of the records in the EU28. Figure 6a,b gives more details on the share of each European country in the EU28. One emerging trend is the increase of soya records, becoming more important than pulse records for the Netherlands and Romania, and near equal for Belgium, Denmark, and Austria. Poland, France, and the UK are countries with the highest proportion of pulse records compared to soya records. Overall, the ranking of European countries is stable over time, apart from the UK whose number of records is smaller in the current decade. Currently, Spain is the top European country on pulses regarding the number of publications, and it is also the top European country for pulse cultivation and consumption (Eurostats). 


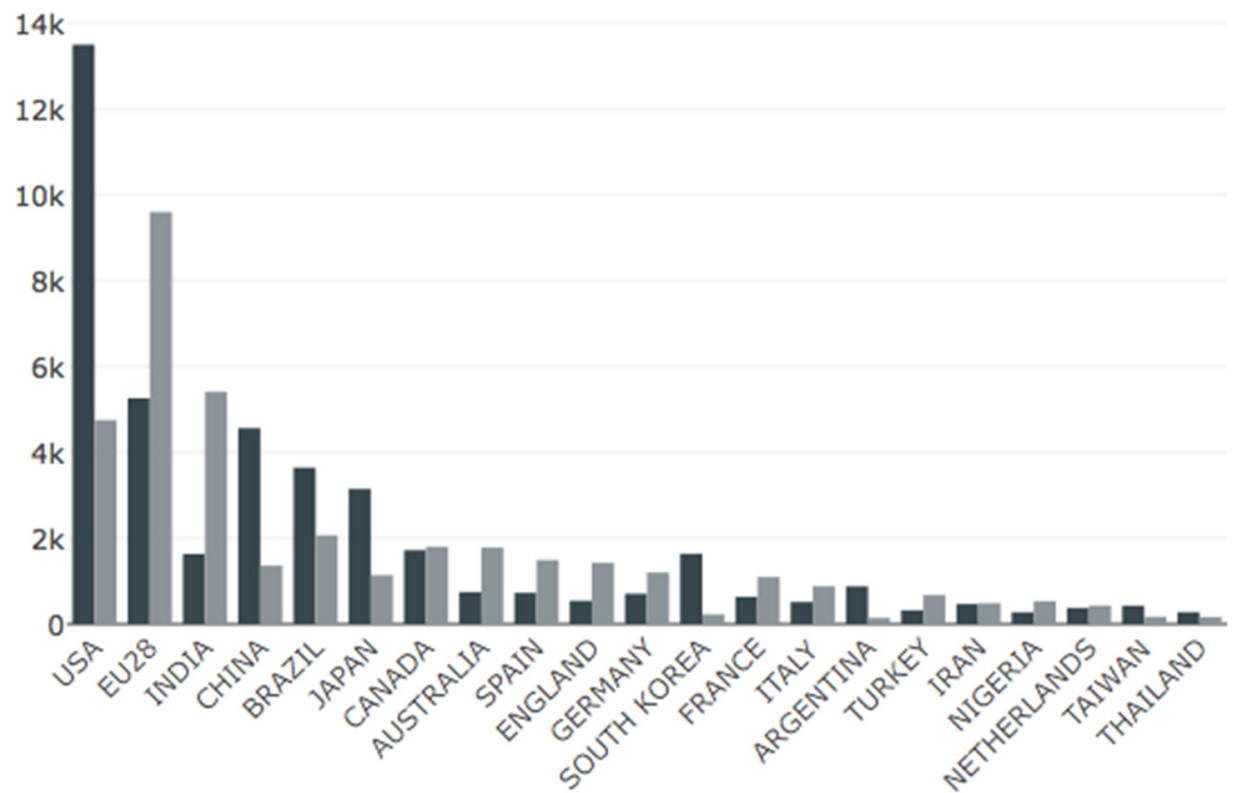

(a)

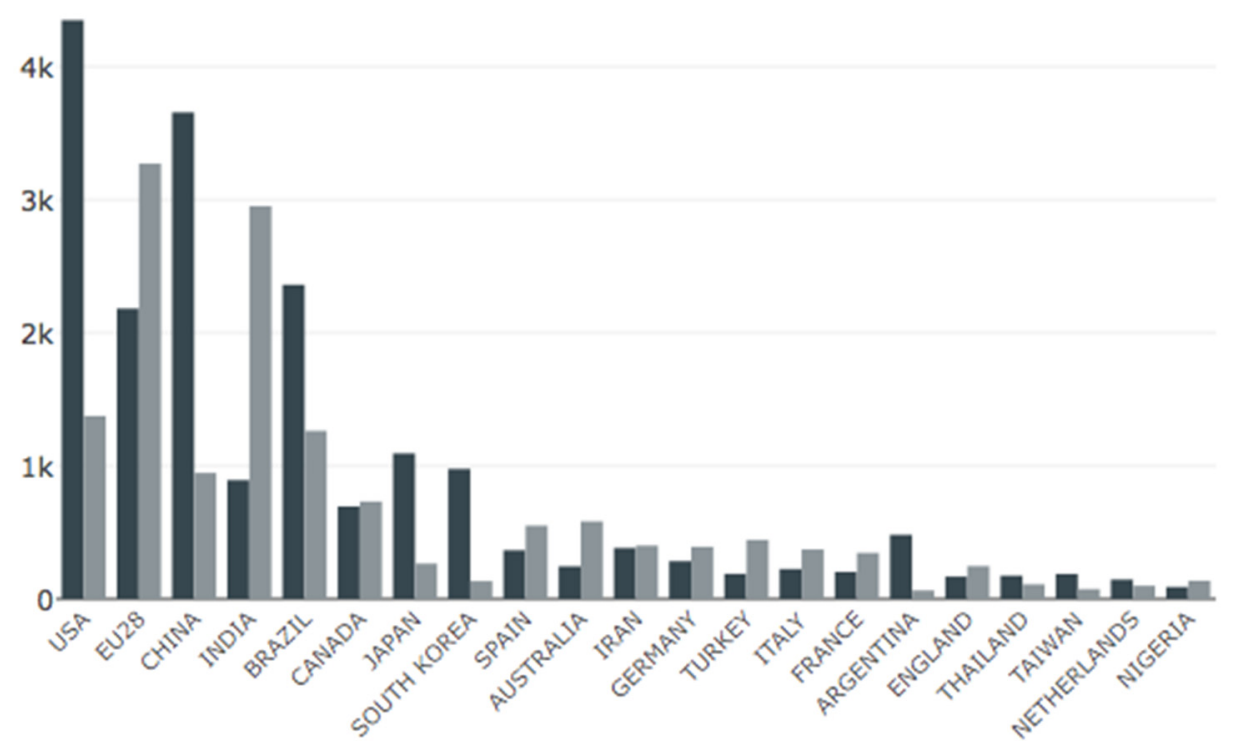

Soya

Pulses

(b)

Figure 5. Soya and Pulses records across countries in the Fusion corpus. (a) 1980-2018. (b) 2010-2018. Note: the 20 highest frequencies are based on total records by country, a group count done for the EU28. Only records indexed with soya or with pulses were included (i.e., records co-indexed with several groups of grain-legumes were excluded). Proportional count for international collaboration records is applied. The country ranking is based on the total records number by country. 


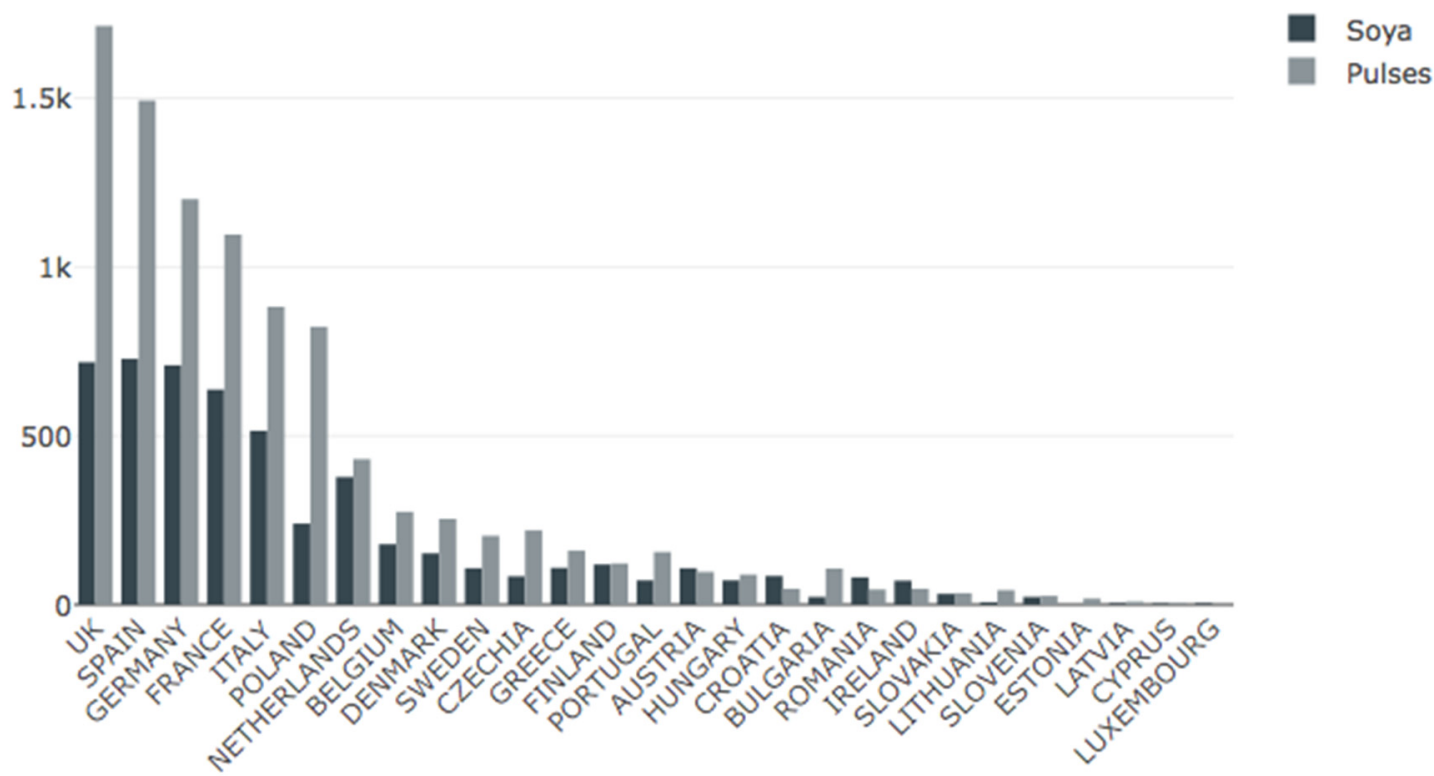

(a)

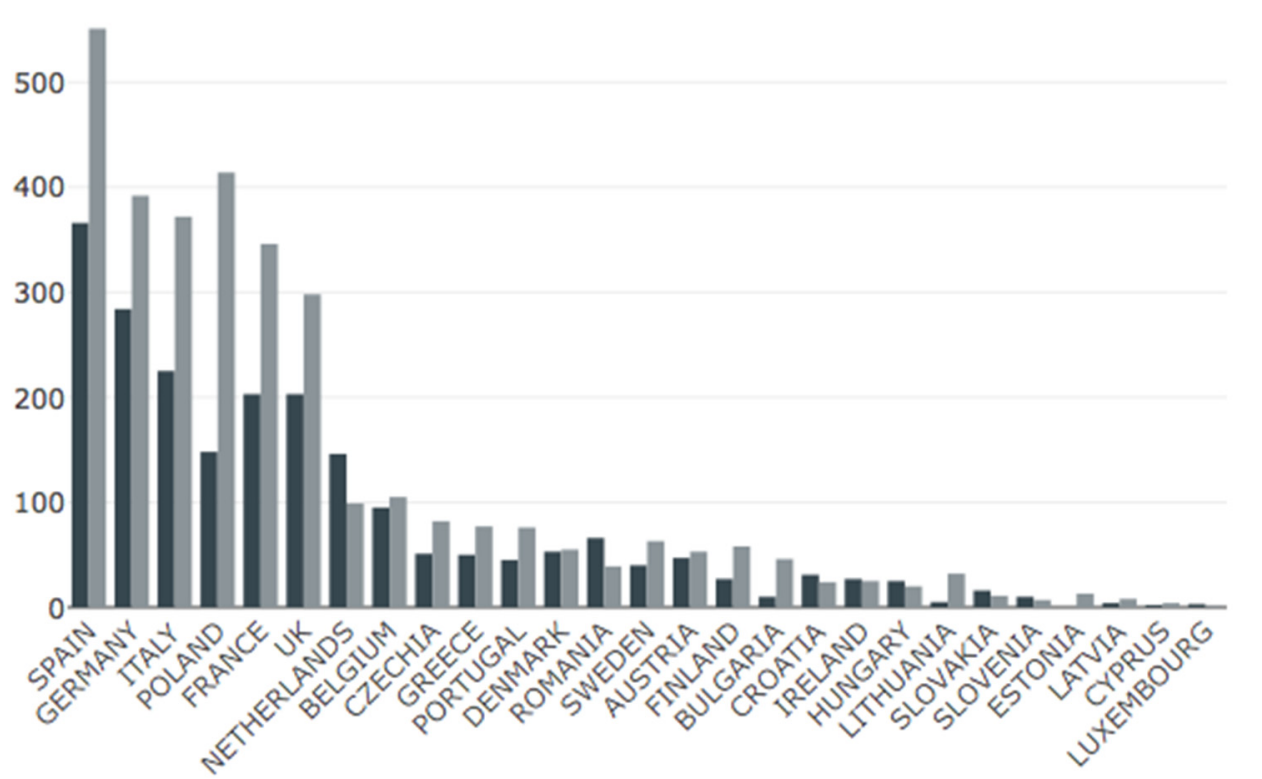

(b)

Figure 6. Soya and Pulses records across the EU28 countries in the Fusion corpus. (a) 1980-2018. (b) 2010-2018. Note: only records indexed with soya or with pulses were included (i.e., records co-indexed with several groups of grain-legumes were excluded). Proportional count for international collaboration records is applied. The country ranking is based on the total records number. Malta had no records. 
Table 6. The eight main areas/countries publishing the most on pulses or soya.

\begin{tabular}{|c|c|c|c|c|c|c|c|c|c|c|c|c|c|c|c|c|c|c|c|}
\hline \multirow{2}{*}{$\begin{array}{c}\text { Area } \\
\text { Rank * }\end{array}$} & \multirow{2}{*}{$\begin{array}{l}\text { Area or } \\
\text { Country }\end{array}$} & \multicolumn{6}{|c|}{ 1980-2018 Period } & \multicolumn{6}{|c|}{ 1980-2009 Period } & \multicolumn{6}{|c|}{ 2010-2018 Period } \\
\hline & & $\mathrm{S} / \mathrm{P}$ & $\%$ & $\mathrm{~S}$ & $\%$ & $\mathbf{P}$ & $\%$ & $\mathbf{S}$ & $\%$ & $\mathrm{~S}$ & $\%$ & $\mathbf{P}$ & $\%$ & $\mathrm{~S} / \mathrm{P}$ & $\%$ & $\mathrm{~S}$ & $\%$ & $\mathbf{P}$ & $\%$ \\
\hline 1 & USA & 18,238 & $24 \%$ & 13,487 & $33 \%$ & 4751 & $13 \%$ & 12,524 & $30 \%$ & 9148 & $42 \%$ & 3376 & $17 \%$ & 5714 & $16 \%$ & 4339 & $22 \%$ & 1375 & $9 \%$ \\
\hline 2 & UE28 & 14,854 & $19 \%$ & 5260 & $13 \%$ & 9594 & $27 \%$ & 9401 & $22 \%$ & 3078 & $14 \%$ & 6323 & $31 \%$ & 5453 & $16 \%$ & 2182 & $11 \%$ & 3271 & $21 \%$ \\
\hline 4 & INDIA & 043 & $9 \%$ & 1634 & $4 \%$ & 5409 & $15 \%$ & 3198 & $8 \%$ & 741 & $3 \%$ & 2457 & $12 \%$ & 3845 & $11 \%$ & 893 & $5 \%$ & 2952 & $19 \%$ \\
\hline 3 & CHINA & 5926 & $8 \%$ & 4564 & $11 \%$ & 1362 & $4 \%$ & 1323 & $3 \%$ & 908 & $4 \%$ & 415 & $2 \%$ & 4603 & $13 \%$ & 3656 & $19 \%$ & 947 & $6 \%$ \\
\hline 5 & BRAZIL & 5712 & $7 \%$ & 3645 & $9 \%$ & 2067 & $6 \%$ & 2088 & $5 \%$ & 1284 & $6 \%$ & 804 & $4 \%$ & 3624 & $10 \%$ & 2361 & $12 \%$ & 1263 & $8 \%$ \\
\hline 6 & JAPAN & 4286 & $6 \%$ & 3147 & $8 \%$ & 1139 & $3 \%$ & 2926 & $7 \%$ & 2053 & $9 \%$ & 873 & $4 \%$ & 1360 & $4 \%$ & 1094 & $6 \%$ & 266 & $2 \%$ \\
\hline 7 & CANADA & 3524 & $5 \%$ & 1722 & $4 \%$ & 1802 & $5 \%$ & 2097 & $5 \%$ & 1027 & $5 \%$ & 1070 & $5 \%$ & 1427 & $4 \%$ & 695 & $4 \%$ & 732 & $5 \%$ \\
\hline 8 & AUSTRALIA & 2530 & $3 \%$ & 747 & $2 \%$ & 1783 & $5 \%$ & 1702 & $4 \%$ & 502 & $2 \%$ & 1200 & $6 \%$ & 828 & $2 \%$ & 245 & $1 \%$ & 583 & $4 \%$ \\
\hline & CAI $* *$ & 62113 & $80 \%$ & 34206 & $83 \%$ & 27.907 & $78 \%$ & 35,259 & $84 \%$ & 201 & & & & $20,00 x$ & $76 \%$ & 1546 & $79 \%$ & 11,389 & $73 \%$ \\
\hline & TAL $* * *$ & 77,170 & $100 \%$ & 41,413 & $100 \%$ & 35,757 & $100 \%$ & 42,014 & $100 \%$ & 21,856 & $100 \%$ & 20,158 & $100 \%$ & 35,156 & $100 \%$ & 19,557 & $100 \%$ & 15,599 & $100 \%$ \\
\hline
\end{tabular}

Note: S means Soya; P means Pulses; S/P considers both. * Area ranking over 1980-2018 for Soya and Pulses records. ${ }^{* *}$ suBtotaL corresponds to the sum of the eight main areas/countries. *** TOTAL corresponds to all countries. Number of records indexed either with soya (only) or with pulses (only), with proportional count for international collaboration records. These counts were applied on a subset of the Fusion corpus as authors' countries were not identified for nearly 13,000 records indexed with soya or pulses. 


\subsubsection{International Collaboration Research Is Increasing, but Unevenly on Soya or Pulses}

The records involving several countries (international collaboration records) amount to $19 \%$ of the records indexed with soya or pulses (16\% before 2010 and $23 \%$ in the current decade). We identified 3495 combinations of countries among those collaborations and most of those involved two countries. Figure $7 \mathrm{a}, \mathrm{b}$ shows the most frequent collaborations on soya or pulses globally. We observed a clear leadership of the USA in those collaborations both for soya and pulses. Although there were fewer international records on pulses than on soya among the 20 most frequent collaborations, over the current decade $26 \%$ of records on pulses involved international collaboration compared with $22 \%$ for soya. This difference at a global scale is due to the increasing collaboration among the EU28 countries, which focus more on pulses than on soya. Over the current decade, this ranking of the most frequent collaborations has remained stable.

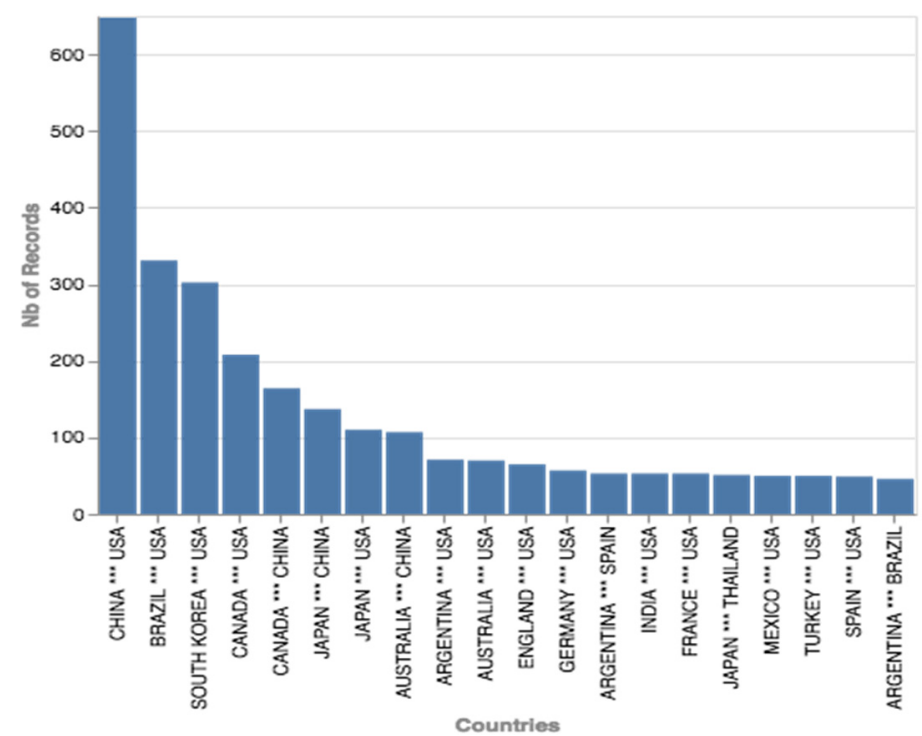

(a)

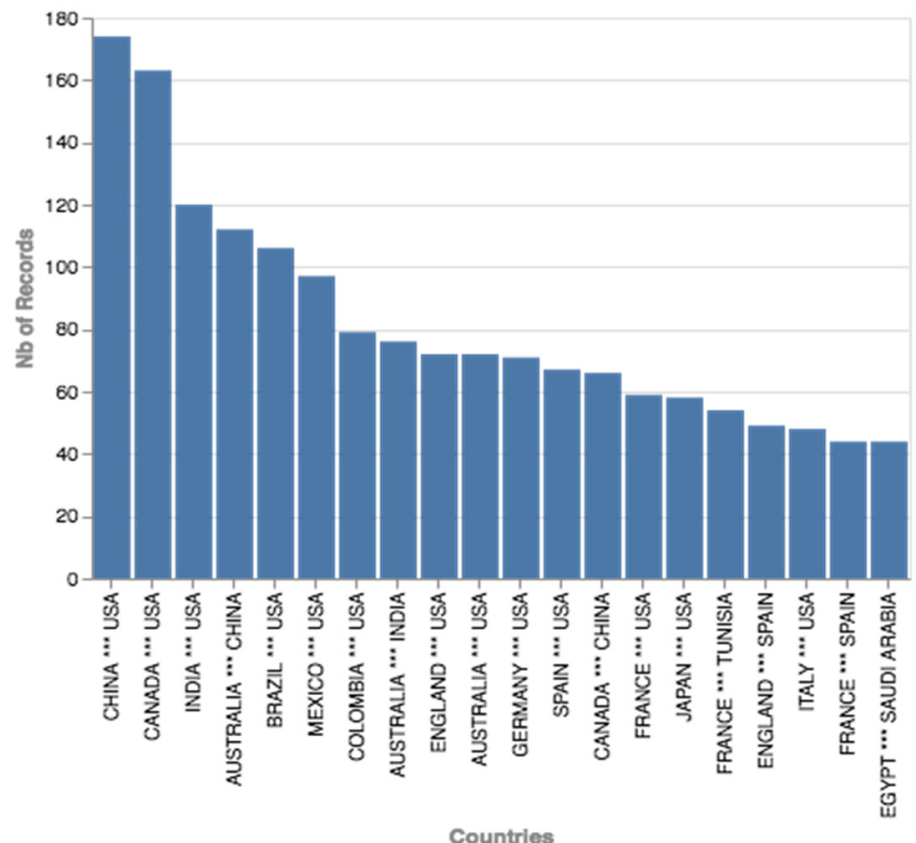

(b)

Figure 7. The 20 most frequent international collaborations 1980-2018 in the Fusion corpus. (a) Most frequent international collaborations on soya. (b) Most frequent international collaborations on pulses. 
The counts in Figure 7a,b correspond to the number of records indexed with soya (only) and with pulses (only), respectively, and for which the authors were only from the countries specified in the horizontal axis. In the WoS, the country indexing is alphabetically ordered and does not correspond to the authors' order in records.

\subsection{Percentage of Themes in the Soya and Pulses Literature}

Figure 8 presents the shares of the 10 themes considered in the Fusion corpus for soya and pulses. First, the breakdown of themes differed for soya and pulses, even in recent years: Processing and NutRITION were more frequent themes for soya than for pulses. In addition, while total records for soya are slightly greater than for all pulses (see Section 3.1), "upstream" themes-such as Genetics, Ecophysiology, BioticStress and Agronomy - had a few more records for pulses than soya. These comparative figures clearly highlight the fact that "downstream" themes are less invested for pulses compared to soya. Moreover, as mentioned above, while feeding is a major outlet for soya, this theme did not represent a large share of the research on soya. However, records on feeding for soya double the number of records for pulses on the same theme. The remaining minor themes, such as ACCEPTABILITY and Allergy, were more developed for soya than for pulses, even in the recent period.

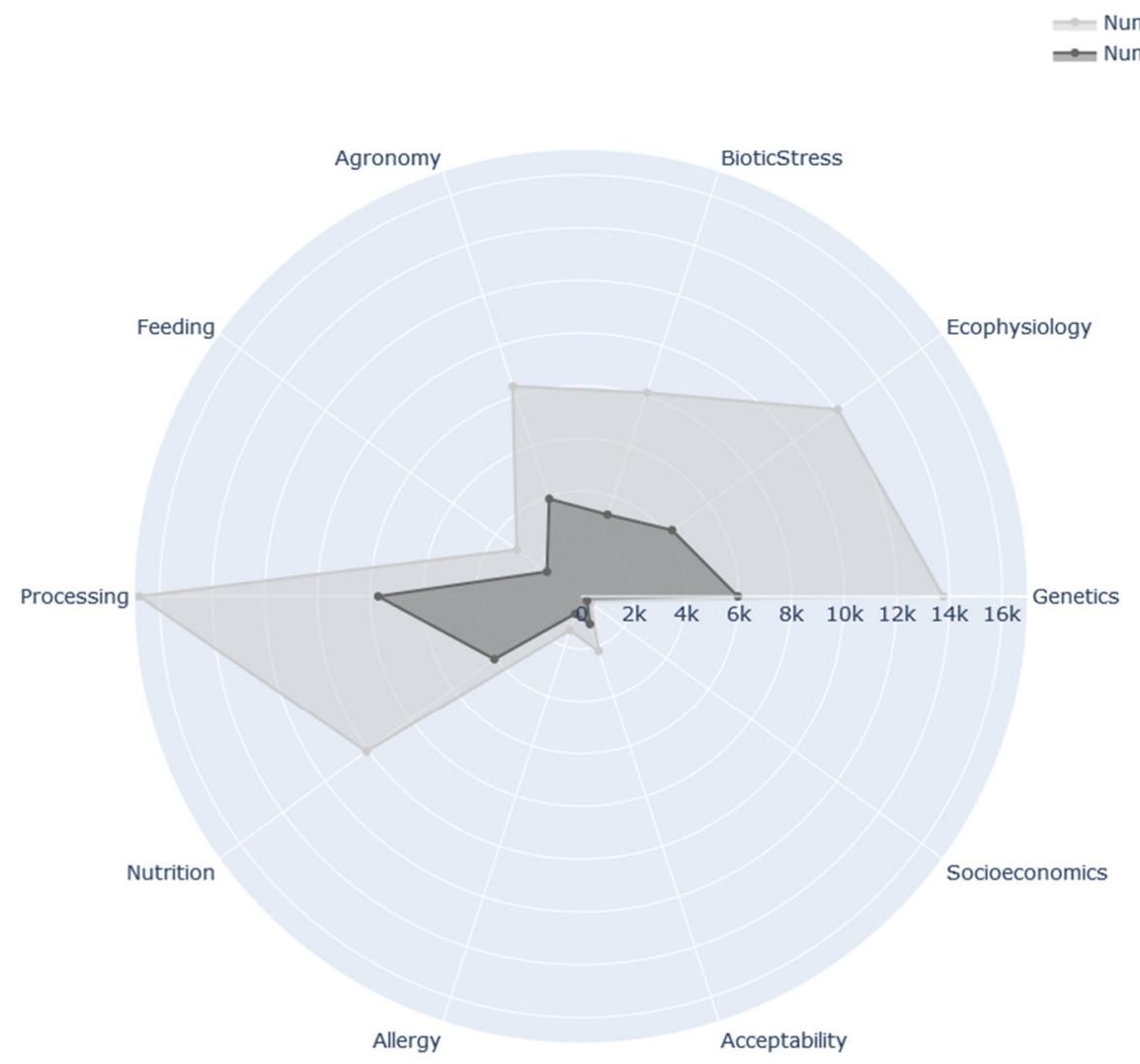

(a)

Figure 8. Cont. 


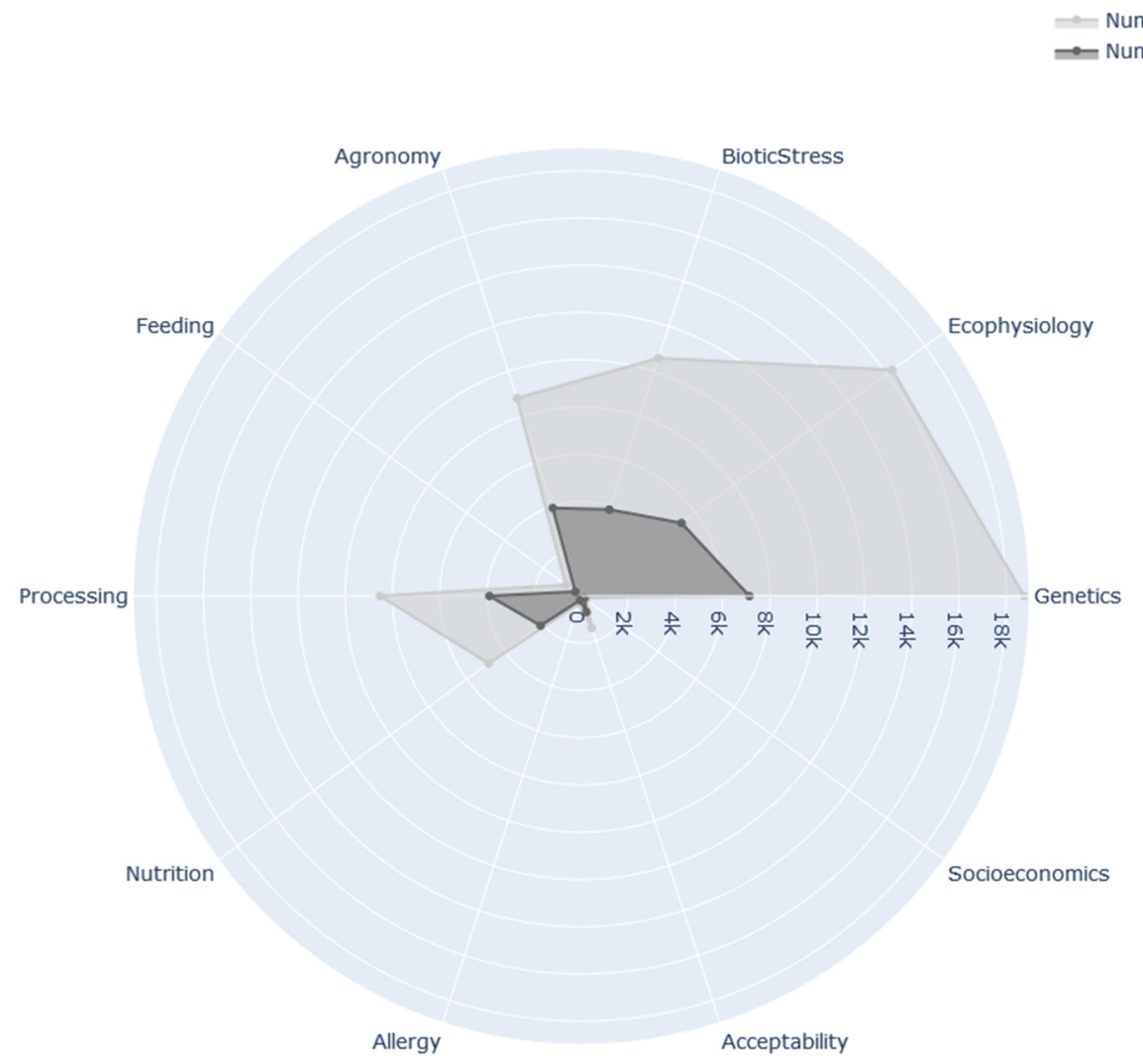

(b)

Figure 8. Shares of themes within records in the Fusion corpus over 1980-2018 and 2010-2018. (a)

Records on soya. (b) Records on pulses.

The results show that the USA, the EU28, India, and China are the four main countries/areas publishing on soya or pulses (Table 6). We calculated the thematic shares for those main countries/areas compared to all other countries to illustrate the variation of themes investigated for pulses and soya (Figure A2). On average, while compared to the USA the EU28 globally focused more on pulses than on soya, for some themes, the gap between them is smaller. For instance, in Genetics and BioticStress, the USA worked on these themes for pulses as much as the EU28 did, while for soya the EU28 published little on these subjects.

Some themes have varying interest by countries. For instance, considering China's strong and recent focus on soya, the most investigated themes are, respectively: Processing, Genetics, Ecophysiology, Nutrition, and BioticStress. For the USA, these come in a different order: Genetics, Ecophysiology, BioticStress, Processing, and Agronomy.

We previously observed that "downstream" themes were less studied for pulses, yet this difference is less pronounced for the EU28 and India. For instance, they focused almost as much on soya as on pulses for Nutrition and Acceptability themes. Therefore, if spatial correlation between the scholarly records on a crop and its level of production in the country seems to be an explanation at first view, further investigation is needed to better understand the variation of themes between soya and pulses according to countries. This could be linked to the research strategies of a specific research team, which would need a socio-semantic network study to uncover fully.

As regards the FeEDING theme, while increasing pulses in feed is an important goal for European public authorities that has led to millions in investments, there is still more research on soya by the EU28 than on pulses, representing about as many records as for the USA. Other countries are much 
involved in soya research for the FeEDING theme, such as the considerable focus in South America (especially Brazil and Argentina).

\subsection{Implications for Future Research Policy on Grain-Legumes}

The shares of crops in research are strongly path-dependent, especially as regards soya and pulses. Soya dominates research on legumes at the global scale whatever the theme, being also the crop with a dominant market size compared to pulses (Appendix A, Table A1). In addition, we observed that the gap between soya and pulses has strongly grown over time for some countries such as China. For instance, when counting the records before 2010 for China, the gap between pulses and soya was not so great, but it strongly increased afterwards. In contrast, for other countries, the gap between soya and pulses has been stable: that is to say, no opposite trend appears between the two periods for any country or theme considered here. Globally, pulses benefit from less research activity than major crops such as soy, as advanced by other works [32]. As regards global plant-based protein markets for food, soya is mainly used in current product innovations compared to pulses [33]. Therefore, since markets do not seem to drive agrofood systems towards more agricultural diversity, this raises questions about how to shift research to provide knowledge that will make a transition towards more grain-legumes crop diversity possible. The present study did not examine research trends according to private or public funding. One possible avenue for future research would be to determine whether public funding favors diversity in agricultural research. Such an investigation would require analyzing the "Funding Acknowledgment Table" indexed by the WoS since 2008, through a list of institution names that need to be standardized for analysis. Finally, the shares of grain-legumes in research activity seems not to be totally dependent on the crop production of the countries and further investigation must be conducted to better analyze for which countries this spatial correlation is stronger.

As the share of research between soya and pulses is highly uneven, it is essential to increase research on pulses including a wide variety of species, compared to soya as a single species, as advocated during the IYP in 2016. One main challenge remains to create links between species, what some researchers call "translational" research. This would require important changes in research. For instance, if the large body of research on agronomy and ecophysiology were more systematically associated with crop modeling, their hypotheses and results would be easier to use for research protocols in other species. As shown by the relatively low number of studies combining at least two pulse species, there is also a need for more comparative analysis across species and for all the themes identified in this study. Research planning and policy should also consider that the model used for oil-legumes, focused on one species (soybean), will not work with pulses, which have strong specificities with regards to consumer preferences and food processing. Public investments and public-private partnerships will be essential to ensure that an increase in pulse research funding does not erode this pulse species diversity. It was outside the scope of this study to analyze financial investments in research on pulses, but the number of publications on these crops, their increase during the last two decades, and the identification of leading countries could support an international approach to the research on these crops. They would be essential components of nutrition sensitive agriculture in the Earth's margins, recently termed "environmental nutrition" [34].

Moreover, as future pulse development would be for food and nutrition, more investment in food sciences, including processing, is crucial for providing diverse pulse-based products that ensure food security and good health. While for upstream themes required to increase production (such as Genetics and Ecophysiology) pulses have received a good deal of attention, more research in food sciences is still needed to develop markets as argued in other studies. The results here show that both Nutrition and Processing themes were strong for soya, while the food outlet for whole-grain soya represents only around 5\% of its production [9]. That is to say, around 15 million tons of soya production is entirely used for food, while the food outlet for pulses is considered to be (at least) around $50 \%$ of the global production, that is, accounting for a higher food outlet of around 50 million tons according to the volumes of those crops (Table A1). However, our study found less research for pulses in 
themes related to food sciences. By creating products meeting food habits and preferences, improving nutritional values, and increasing their usage by renowned food brands, research in processing could be a way to increase pulse consumption, to value under-used pulses species, and finally to build a value chain by making pulses more than a low-cost substitute for animal proteins [35]. A compromise between marketing opportunities and affordable healthy food for consumers should more often be an objective of research in food sciences. Agricultural and food sciences have to work hand in hand for sustainable agriculture, designing coupled innovations between the upstream and downstream of supply chains [36]. Therefore, more publications co-indexed with agricultural and food sciences are expected.

\section{Conclusions}

Understanding the dynamics of research is an epistemic project that concerns all sciences and is one primary focus of STS. Analyzing bibliometric datasets help both decision-makers for science policies and scholars to orient science and, in the end, innovation. By using scientometric indicators on the metadata of scholarly documents retrieved from the WoS, we gave an overview of the research output on grain-legumes since 1980 at the global scale. We quantified the shares of species, analyzed by main academic fields (i.e., themes) and countries. To establish these results, this work developed a rigorous methodology for building a bibliometric dataset and a processing software, which can be used for further bibliometric research on other crops to bring a larger analysis of the dynamics of research activity on agricultural and food systems. We first discuss main implications of this work, and then propose further works to be conducted to improve our analyses.

First, these results show that research on grain-legumes is path-dependent and is strongly linked to the size of their agricultural production, as the main species researched in the past continue to be the main focus of research today. These findings should foster further discussion and reflection among the scientific community about grain-legumes, especially regarding the challenge of greater crop diversity. Above all, researchers must be encouraged to create links among species to enlarge the application of their results, as we found few records mentioning several species together. In addition, while upstream themes have received considerable attention (such as GENETICs and EcopHYsiology), downstream themes have received unequal interest among crops; particularly, compared to soya, pulses have been less researched in relation to downstream themes of food sciences. This imbalance questions the capacity of research to develop knowledge that would enable more food outlets for pulses, as expected by the United Nations during the IYP. Finally, the results show that most research on grain-legumes has been conducted by eight countries/geographical areas (including the European Union). While some geographical areas have done more research on pulses than on soya, such as the EU28 and India, others specialized on soya, such as many American countries. Newcomers such as China clearly made the choice to invest more in research on soya, establishing important collaborations with the USA.

Second, there is a strategic interest in bibliometric studies on the way research is conducted on agricultural and agrofood systems, in order to define new research priorities. This type of work is not an easy task, and collaboration between scientific experts on the themes investigated and experts in scientometrics is essential. Given that we are faced with an ever increasing amount of published data, involving researchers on the measurement of sciences is essential. Moreover, those researchers could advise other researchers on the way to communicate about their work. Indeed, the way bibliometric datasets are collected and how researchers describe their works through the title, abstract, and keywords of records impact the ways we can analyze research patterns through bibliometric data. Title, abstract, and keywords are the main data on which scientometric studies relies, and thus their contents strongly determine the results obtained. Our findings raise another question about the way species are mentioned: a common dictionary of species names in scientific platforms, such as the WoS, would help to better follow species, and to conduct longitudinal analysis on the percentage of any crop in research and their links. 
Thirdly, we used English-language scholarly publications, such as peer-reviewed articles, books, and book chapters, to reflect research activity and to give an overview of the majority of the scientific knowledge on grain-legumes. Other data collections could enrich our dataset to have a more complete overview. The first improvement will be to add records retrieved from the Scopus Collection (the other most used bibliometric platform), even though the WoS and Scopus overlap considerably for certain disciplines [26]. This could lead to some adjustments in the shares of themes, but probably not in their ranking. Other enrichments such as using alternative search engines, e.g., Google Scholar (GS), will require methodological solutions. GS provides access to larger collection of research such as $\mathrm{PhD}$ theses, scientific reports, and non-peer-reviewed articles, but no software exists to retrieve large collections from GS. In addition, no rigorous metadata are associated to enable relevant analysis among the various documents once they are collected. Last, while English dominates scientific publications, other languages are still used and including them would complicate larger record harvesting and analyses from GS. "The second most frequent language of unique GS citations was Chinese (4-12\%), and all other languages have a share of $4 \%$ or lower across all subject areas. A few (5-10\%) unique GS citations were published in languages outside the top 11 most frequently used languages overall" [26] (p. 14).

To have a better overview of the evolution of this scholarly scientific knowledge on grain-legumes, further studies can be done (based on this dataset or an enriched dataset) such as semantic or socio-semantic network analysis. Co-words and institution mapping would provide overviews of the main and minor concepts and knowledge that characterize research according to species, themes, and countries. By identifying the main relationships between terms, bridges of knowledge and new research areas can be identified within and among species. In particular, as grain-legumes are recognized to have a high potential for more sustainable agriculture, it would be interesting to analyze the development of specific targets and wordings aiming at increasing the role of these species in a sustainable agricultural production, for both food and feed.

Lastly, understanding the relationships between markets trends and research directions remains a main challenge of the STS. Future works could analyze the spatial correlation between scholarly documents on crops and the crops production/consumption levels within countries to analyze links between research activity and societal demands, as recently conducted on rice species [37]. Considering also the metadata associated to funding in notices (indexed in the WoS since 2008) will allow evaluating the shares of independent research (i.e., non-commercial funding) compared to other private-based funding, and could reveal different research trajectories regarding the specialization vs. diversification of crops under research.

Author Contributions: Conceptualization, M.-B.M. and G.C.; Data curation, M.-B.M., G.C., M.L., H.L. and D.M.; Formal analysis, M.-B.M., G.C., M.L., M.-J.A., M.A., G.A., A.B., L.B., J.-M.C., G.D., M.-H.J., E.-P.J., H.J., C.L., H.L., V.M., D.M., M.-L.P.-N., C.N.-T., T.S., A.-S.V., S.W. and J.W.; Funding acquisition, M.-B.M.; Investigation, M.-B.M., G.C. and M.L.; Methodology, M.-B.M., G.C., M.L., M.-J.A., M.A., G.A., A.B., L.B., J.-M.C., G.D., M.-H.J., E.-P.J., H.J., C.L., H.L., V.M., D.M., M.-L.P.-N., C.N.-T., T.S., A.-S.V., S.W. and J.W.; Project administration, M.-B.M.; Resources, M.-B.M. and G.C.; Software, G.C.; Supervision, M.-B.M.; Validation, M.-B.M., G.C., M.L., G.P., M.-J.A., M.A., G.A., A.B., L.B., J.-M.C., G.D., M.-H.J., E.-P.J., H.J., C.L., H.L., V.M., D.M., M.-L.P.-N., C.N.-T., A.-S.V., S.W. and J.W.; Visualization, M.-B.M., G.C., H.L. and T.S.; Writing-original draft, M.-B.M., G.C. and G.P.; and Writing-review and editing, M.-B.M., G.C., M.L., G.P., M.-J.A., M.A., G.A., A.B., L.B., J.-M.C., G.D., M.-H.J., E.-P.J., H.J., C.L., H.L., V.M., D.M., M.-L.P.-N., C.N.-T., A.-S.V., S.W. and J.W.

Funding: This work was supported by funding from the European Union's Horizon 2020 research and innovation program under grant agreement No. 727672-LEGVALUE (Fostering sustainable legume-based farming systems and agri-feed and food chains in the EU); from the Agence Nationale de la Recherche (ANR) under grant number ANR-11-LABX-0066; and by the French National Institute for Agricultural Research (INRA).

Acknowledgments: The authors acknowledge the two anonymous reviewers whose comments and suggestions helped sharpen the argument, and Cynthia J. Johnson for her helpful comments and English editing of the manuscript.

Conflicts of Interest: The authors declare no conflict of interest. 


\section{Appendix A}

Table A1. Global production of main pulses, soya and cereals, trienniums ending 1971, 1981, 1991, 2001, 2011, and 2017 (million metric tons). Source: FAOstat.

\begin{tabular}{ccccccc}
\hline \multirow{2}{*}{ Species } & \multicolumn{7}{c}{ Year } \\
\cline { 2 - 7 } & $\mathbf{1 9 7 1}$ & $\mathbf{1 9 8 1}$ & $\mathbf{1 9 9 1}$ & $\mathbf{2 0 0 1}$ & $\mathbf{2 0 1 1}$ & $\mathbf{2 0 1 7}$ \\
\hline Bean (dry) & 12 & 15 & 18 & 18 & 24 & 34 \\
Chickpea & 6 & 5 & 8 & 6 & 11 & 14 \\
Pea (dry) & 9 & 7 & 12 & 10 & 10 & 16 \\
Faba/broadbean & 8 & 8 & 6 & 8 & 8 & 8 \\
Lentil & 1 & 1 & 2 & 3 & 4 & 7 \\
Pigeon pea & 2 & 2 & 2 & 3 & 4 & 6 \\
Cowpea & 1 & 1 & 2 & 3 & 4 & 7 \\
Vetches & 1 & 1 & 1 & 1 & 1 & 1 \\
Lupin & 0.3 & 1 & 1 & 1 & 1 & 1 \\
Bambara Bean & 0.03 & 0.03 & 0.08 & 0.08 & 0.14 & 0.18 \\
Other pulses & 3 & 2 & 4 & 3 & 3 & 4 \\
Total Pulses & 42 & 41 & 56 & 56 & 69 & 95 \\
Soya & 45 & 88 & 102 & 177 & 261 & 352 \\
Cereals & 1229 & 1632 & 1890 & 2104 & 2588 & 2980 \\
\hline
\end{tabular}

Table A2. Links to the 11 WoS queries designed to delineate the corpus under study, each query capturing thematic corpus on grain-legumes (e.g., Allergy and BioticStress). The Species query was combined to thematic queries or used isolated.

\begin{tabular}{|c|c|}
\hline Query Name & Link to the Search Query Applied on the Web of Science (WoS) Core Collection \\
\hline \multicolumn{2}{|r|}{ THE SPECIES SEARCH QUERY } \\
\hline SPECIES & $\begin{array}{c}\text { DUC, Gérard; WERY, Jacques; MAGRINI, Marie-Benoit; CABANAC, Guillaume, 2019, } \\
\text { “Grain-Legumes Species WoS DataSet 1980-2018”, https://doi.org/10.15454/QBQFCX, Portail } \\
\text { Data Inra }\end{array}$ \\
\hline \multicolumn{2}{|r|}{ THE 10 THEMATIC SEARCH QUERIES } \\
\hline GENETICS & $\begin{array}{l}\text { DUC, Gérard; WERY, Jacques; MILLOT, Dominique; CABANAC, Guillaume, 2019, “Genetics } \\
\text { and Grain-Legumes WoS DataSet 1980-2018", https://doi.org/10.15454/PFV9JK, Portail Data Inra }\end{array}$ \\
\hline AGRONOMY & $\begin{array}{l}\text { JEUFFROY, Marie-Hélène; BEDOUSSAC, Laurent; MILLOT, Dominique; CABANAC, } \\
\text { Guillaume, 2019, “Agronomy and Grain-Legumes WoS DataSet 1980-2018”, } \\
\text { https://doi.org/10.15454/W6BAUG, Portail Data Inra }\end{array}$ \\
\hline ECOPHYSIOLOGY & $\begin{array}{c}\text { VOISIN, Anne-Sophie; JOURNET, Etienne-Pascal; LEISER, Hugues; CABANAC, Guillaume, } \\
\text { 2019, “Ecophysiology and Grain-Legumes WoS DataSet 1980-2018”, } \\
\text { https://doi.org/10.15454/FOCNNS, Portail Data Inra }\end{array}$ \\
\hline BIOTICSTRESS & $\begin{array}{c}\text { BARANGER, Alain; PILET-NAYEL, Marie-Laure; MILLOT, Dominique; CABANAC, Guillaume, } \\
\text { 2019, "Biotic Stress and Grain-Legumes WoS DataSet 1980-2018”, } \\
\text { https://doi.org/10.15454/L79X2K, Portail Data Inra }\end{array}$ \\
\hline FEEDING & $\begin{array}{l}\text { JUIN, Hervé; LEISER, Hugues; CABANAC, Guillaume, 2019, “Feeding and Grain-Legumes WoS } \\
\text { DataSet 1980-2018”, https://doi.org/10.15454/BNKFVC, Portail Data Inra }\end{array}$ \\
\hline PROCESSING & $\begin{array}{c}\text { ANTON, Marc; MICARD, Valérie; NGUYEN-THE, Christophe; LEISER, Hugues; CABANAC, } \\
\text { Guillaume, 2019, “Processing and Grain-Legumes WoS DataSet 1980-2018”, } \\
\text { https://doi.org/10.15454/VP7PRI, Portail Data Inra }\end{array}$ \\
\hline NUTRITION & $\begin{array}{c}\text { AMIOT-CARLIN, Marie-Josephe; CHARDIGNY, Jean-Michel; WALRAND, Stéphane; LEISER, } \\
\text { Hugues; CABANAC, Guillaume, 2019, “Nutrition and Grain-Legumes WoS DataSet 1980-2018”, } \\
\text { https://doi.org/10.15454/5MI04S, Portail Data Inra }\end{array}$ \\
\hline ALLERGY & $\begin{array}{l}\text { LARRE, Colette; DENERY, Sandrine; LESIER, Hugues; CABANAC, Guillaume, 2019, “Allergy } \\
\text { and Grain-Legumes WoS DataSet 1980-2018”, https://doi.org/10.15454/BZG0R7, Portail Data Inra }\end{array}$ \\
\hline ACCEPTABILITY & $\begin{array}{l}\text { ARVISENET, Gaelle; MAGRINI, Marie-Benoit; LEISER, Hugues; CABANAC, Guillaume, 2019, } \\
\text { "Acceptability and Grain-Legumes WoS DataSet 1980-2018”, https://doi.org/10.15454/PDXRYM, } \\
\text { Portail Data Inra }\end{array}$ \\
\hline SOCIOECONOMICS & $\begin{array}{c}\text { Magrini, Marie-Benoit; Plumecocq, Gael; Leiser, Hugues; Cabanac, Guillaume, 2019, } \\
\text { “Socioeconomics and Grain-Legumes WoS DataSet 1980-2018”, https://doi.org/10.15454/JNIPX5, } \\
\text { Portail Data Inra }\end{array}$ \\
\hline
\end{tabular}


Table A3. Breakdown of the Fusion corpus in the 10 underlying themes (single or combined themes indexed).

\begin{tabular}{|c|c|c|c|c|c|c|c|c|c|c|c|c|c|c|c|c|}
\hline \multirow[b]{2}{*}{$\begin{array}{l}\text { Themes Index } \\
\text { Colum A }\end{array}$} & \multirow[b]{2}{*}{$\begin{array}{c}\text { Records } \\
\text { Number } \\
\text { Indexed } \\
\text { with a } \\
\text { Single } \\
\text { Theme * }\end{array}$} & \multirow[b]{2}{*}{$\begin{array}{l}\text { Frequency } \\
\text { Ranking } \\
\text { of the } \\
\text { Single } \\
\text { Theme }\end{array}$} & \multicolumn{14}{|c|}{ Other Themes Index Combined with the Theme in Colum A ${ }^{* *}$} \\
\hline & & & $\begin{array}{l}\text { 1st } \\
\text { Most } \\
\text { Freq. }\end{array}$ & $\begin{array}{l}\text { Nb. } \\
\text { Records }\end{array}$ & $\begin{array}{l}\text { 2nd Most } \\
\text { Freq. }\end{array}$ & $\begin{array}{l}\mathrm{Nb} . \\
\text { Records }\end{array}$ & $\begin{array}{l}\text { 3nd Most } \\
\text { Freq. }\end{array}$ & $\begin{array}{c}\mathrm{Nb} . \\
\text { Records }\end{array}$ & $\begin{array}{l}\text { 4th Most } \\
\text { Freq. }\end{array}$ & $\begin{array}{l}\mathrm{Nb} . \\
\text { Records }\end{array}$ & $\begin{array}{l}\text { 5th Most } \\
\text { Freq. }\end{array}$ & $\begin{array}{c}\mathrm{Nb} . \\
\text { Records }\end{array}$ & $\begin{array}{l}\text { 6th Most } \\
\text { Freq. }\end{array}$ & $\begin{array}{c}\mathrm{Nb.} \\
\text { Records }\end{array}$ & $\begin{array}{l}\text { Total nb } \\
\text { of } \\
\text { Records } \\
\text { Indexed } \\
\text { with the } \\
\text { Theme of } \\
\text { Column A }\end{array}$ & $\begin{array}{l}\text { Share } \\
\text { of } \\
\text { Themes }\end{array}$ \\
\hline Genetics & 13,336 & 1 & Ecophy. & 6845 & BioticS. & 4887 & Agro. & 2176 & $\begin{array}{l}\text { Agro. \& } \\
\text { Ecophy. }\end{array}$ & 1250 & $\begin{array}{l}\text { Ecophy. \& } \\
\text { BioticS. }\end{array}$ & 1119 & Process. & 977 & 34,388 & $22 \%$ \\
\hline $\begin{array}{l}\text { Ecophysiology } \\
\text { (Ecophy.) }\end{array}$ & 12,841 & 2 & Genetics & 6845 & Agro. & 3263 & BioticS.s & 1411 & $\begin{array}{l}\text { Agro. \& } \\
\text { Genetics }\end{array}$ & 1250 & $\begin{array}{c}\text { BioticS. \& } \\
\text { Genetics }\end{array}$ & 1119 & Process. & 878 & 29,867 & $19 \%$ \\
\hline $\begin{array}{c}\text { Processing } \\
\text { (Process.) }\end{array}$ & 12,049 & 3 & Nutrition & 5965 & Accep. & 1298 & $\begin{array}{l}\text { Nutrition } \\
\text { \& Accept. }\end{array}$ & 1046 & Allergy & 1015 & Genetics & 977 & Ecophy. & 878 & 27,180 & $17 \%$ \\
\hline $\begin{array}{c}\text { BioticStress } \\
\text { (BioticS.) }\end{array}$ & 9109 & 4 & Genetics & 4887 & Ecophy. & 1411 & Agro. & 1556 & $\begin{array}{c}\text { Ecophy. \& } \\
\text { Genetics }\end{array}$ & 1119 & $\begin{array}{l}\text { Accept. \& } \\
\text { Nutrition }\end{array}$ & 1046 & $\begin{array}{l}\text { Agro. \& } \\
\text { Genetics }\end{array}$ & 583 & 20,243 & $13 \%$ \\
\hline $\begin{array}{c}\text { Agronomy } \\
\text { (Agro.) }\end{array}$ & 7982 & 5 & Ecophy. & 3263 & Genetics & 2176 & BioticS. & 1556 & $\begin{array}{c}\text { Ecophy. \& } \\
\text { Genetics }\end{array}$ & 1250 & $\begin{array}{c}\text { BioticS. \& } \\
\text { Genetics }\end{array}$ & 583 & Process. & 505 & 19,070 & $12 \%$ \\
\hline Nutrition & 4866 & 9 & Process. & 5965 & $\begin{array}{l}\text { Accept. \& } \\
\text { Process. }\end{array}$ & 1046 & $\begin{array}{l}\text { Genetics \& } \\
\text { Process. }\end{array}$ & 606 & Genetics & 578 & Ecophy. & 238 & $\begin{array}{c}\text { Ecophy. \& } \\
\text { Process. }\end{array}$ & 214 & 15,383 & $10 \%$ \\
\hline Feeding & 2888 & 11 & Genetics & 181 & Process. & 147 & Nutrition & 113 & $\begin{array}{l}\text { Nutrition } \\
\text { \& Process. }\end{array}$ & 80 & Agro. & 42 & Ecophysiology & 36 & 3654 & $2 \%$ \\
\hline Allergy & 1891 & 13 & Process. & 1015 & $\begin{array}{l}\text { Nutrition } \\
\text { \& Process. }\end{array}$ & 191 & Nutrition & 148 & Genetics & 59 & $\begin{array}{c}\text { Genetics \& } \\
\text { Process. }\end{array}$ & 28 & $\begin{array}{l}\text { Genetics \& } \\
\text { Nutrition }\end{array}$ & 27 & 3650 & $2 \%$ \\
\hline $\begin{array}{l}\text { Acceptability } \\
\text { (Accept.) }\end{array}$ & 745 & 23 & Process. & 1298 & $\begin{array}{l}\text { Nutrition } \\
\text { \& Process. }\end{array}$ & 1046 & Nutrition & 194 & $\begin{array}{c}\text { Genetics \& } \\
\text { Process. }\end{array}$ & 105 & Genetics & 90 & $\begin{array}{l}\text { Genetics \& } \\
\text { Nutrition }\end{array}$ & 81 & 3972 & $3 \%$ \\
\hline $\begin{array}{c}\text { Socioeconomics } \\
\text { (Socioeco.) }\end{array}$ & 565 & 27 & Agro. & 125 & Process. & 44 & Genetics & 33 & $\begin{array}{l}\text { Agro. \& } \\
\text { Ecophy. }\end{array}$ & 31 & $\begin{array}{l}\text { Agro. \& } \\
\text { Genetics }\end{array}$ & 27 & $\begin{array}{l}\text { Accept. \& } \\
\text { Process. }\end{array}$ & 15 & 963 & $1 \%$ \\
\hline SUBTOTAL & 66,272 & & & & & & & & & & & & & & & \\
\hline in $\%$ of corpus & $61 \%$ & & & & & & & & & & & & & & 158,370 & $100 \%$ \\
\hline Total Corpus & 107,823 & & & & & & & & & & & & & & & \\
\hline
\end{tabular}




\section{Appendix B. Robustness Assessment of the Delineation Process: Testing an Alternative Strategy}

We experimented with an alternative search strategy using the WoS to delineate a core scientific literature dataset on grain-legumes. As explained in Section 2, to obtain close links between grain-legumes species and specific thematic terms, we gave preference to the use of the Boolean character NEAR/10 in the search query design of most themes. In that way, the search query matched records whose terms joined by the operator were within 10 words of each other. However, to appreciate the differences in the frequency of records retrieved, depending on the use of the operator NEAR or not, we also built other bibliometric datasets on those grain-legumes, resulting from search queries without the NeAr operator. This other strategy led to the so-called Species1, Species2, and Species3 corpora, following an alternative methodology illustrated in Figure A1. This alternative delineation strategy used the same terms in the search queries than the one exposed in Section 2.

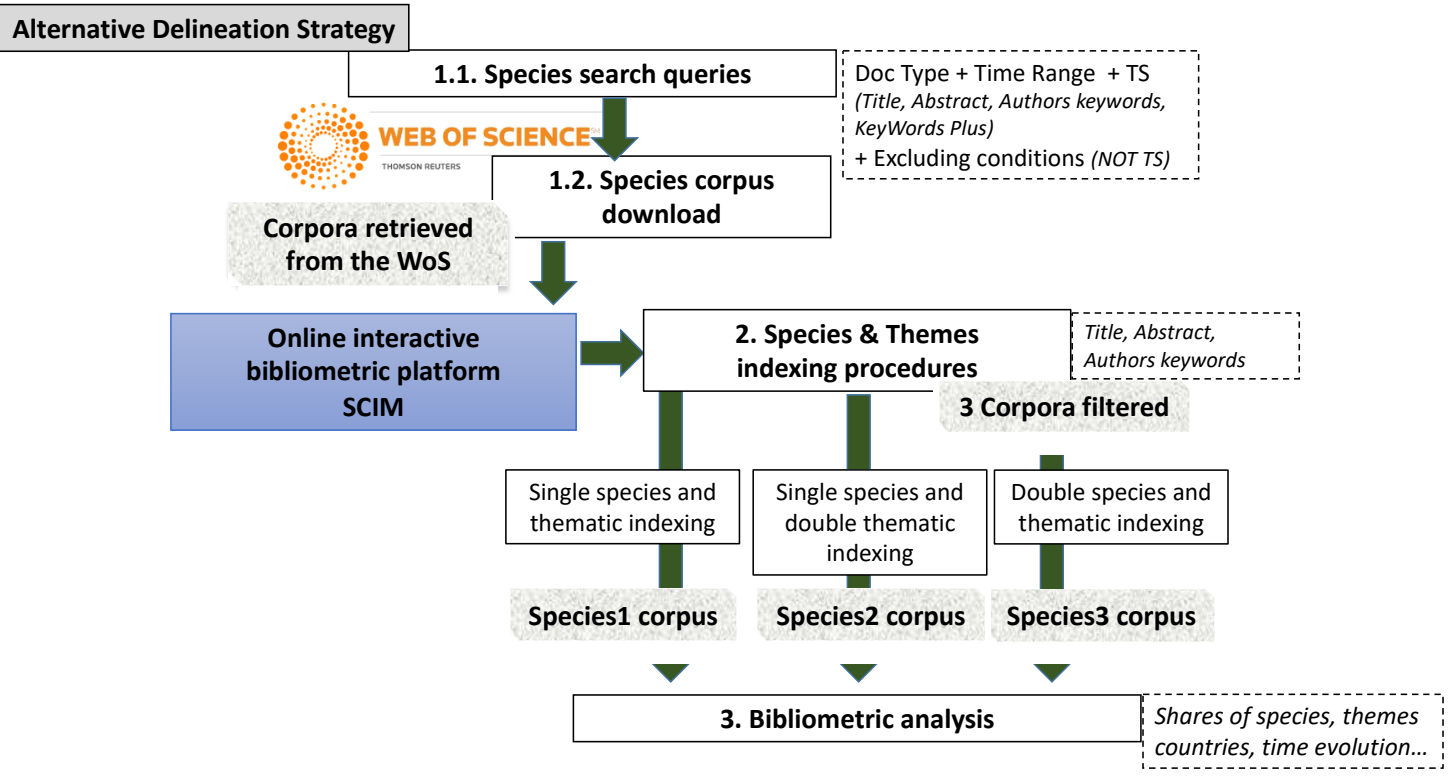

Figure A1. Main steps to build the bibliometric dataset according to an alternative delineation strategy. Figure A1 summarizes the main steps followed to build the corpora quite similar to that of Figure 1 (Section 2), but with a change in the way to design search queries and the indexing procedure. This alternative delineation strategy led to three other corpora called Species1, Species2, and Species3.

SPecies1, Species2, and Species3 are the corpora retrieved from the WoS by using the Species search query only, on which various indexing step strategies were applied. The aforementioned indexing step consists in keeping the records having a term of the search query among the Title, Abstract or Author's keywords only (i.e., filtered from the KeyWord Plus). This also led to indexing each record with the search terms found in Title, Abstract or Author's keywords. First, each record was indexed with one or several legume species according to the Species terms occurring in the record (see Table 3 for species indexation). Second, we indexed each record relatively to the 10 thematic subjects when any of the terms of the records matched the terms of the thematic query (Appendix A, Table A2). In other words, this strategy did not rely on the NEAR operator but on the indexing procedure applied on the SPECIES corpus downloaded from the WoS. The three variants of the SPECiEs corpora were built, depending on the way the indexing procedure was applied:

- Species1 has single species and thematic indexing. A record was indexed with a species term and with a thematic corpus, if at least one term of the species query and at least one term of the thematic query occurred in the record. 
- SPecies2 has single species indexing and double thematic indexing. A record was indexed with a species term and with a thematic corpus, if at least one term of the species query and at least two terms of the thematic query occurred in the record.

- Species3 has both double species and thematic indexing. A record was indexed with a species term and with a thematic corpus, if at least two terms of the species query and at least two terms of the thematic query occurred in the record.

The size of these corpora varied and are reported in Table A4.

We observed that, of course, the more we restricted the strategy on search query and indexing, the fewer records were included. We matched the records between Fusion and Species 3 corpora: we observed a difference of 22,661 records caught by SPECIES3 but not present in Fusion; inversely, 27,813 records were caught by Fusion and not present in SPECIEs3.

However, above all, the correspondence between the wcs and the themes defined by experts was less adequate for the Species1, SPecies2, and SPEcies3 corpora compared to the Fusion corpus. For instance, the classification of the records with the 10 themes investigated by experts was not really relevant in SPECies3, while we observed strong correspondence between the wcs and the thematic indexes in Fusion. Therefore, the forthcoming analysis by themes is more biased in Species3, as this corpus induces a biased representation of the 10 themes compared with Fusion. This was encountered, for instance, with the Nutrition theme that included a lot of records dealing with plant growth and not with human nutrition in SPECIEs3.

For evidence on the stronger relevance of the delineation strategy kept for Fusion Corpus, compared to the alternative delineation strategy, we present Table A5 should the number of records according to thematic indexing, respectively, in the Fusion and SPEcies3 corpora. We observed that in Fusion, the records indexed with a single theme were more frequent $(61 \%)$ than in Species $3(25 \%)$. Hence, the Fusion corpus led to a quite clear thematic classification of the records among the 10 themes investigated, given the fact that among the remaining co-indexed thematic records $30 \%$ were indexed with two themes, and $8 \%$ with three themes. More precisely when considering thematic ranking, in Fusion corpus, the five first thematic indexes frequencies (concerning records indexed with only one theme) were: Genetics, Ecophysiology, Processing, BioticStress and Agronomy. The remaining single theme indexes (Nutrition, Feeding, Allergy, Acceptability, and Socioeconomics) appear with less frequency as there are many fewer records on these themes, and that GenEtics, Ecophysiology, Processing, BioticStress, and Agronomy are themes whose co-indexing between themselves has a high frequency of records (on that point, see Table A3 that presents frequencies on co-indexing themes in the Fusion corpus). In all, these five themes were the most frequent, respectively, $22 \%, 19 \%, 17 \%$, $13 \%$, and $12 \%$.

All these remarks show the importance of the delineation strategy in building a bibliometric corpus. Moreover, it is clear that conducting bibliometric analysis requires considerable support of experts in the scientific themes investigated, since relying on wcs alone is not sufficient to delineate a relevant bibliometric corpus. Consequently, for us, the methodology kept to establish Fusion corpus is the most appropriate for identifying a "core" literature dataset on grain-legumes whose records can be classified by relevant themes (see also Table A3). Notwithstanding, some statistics presented in the Section 3, were also calculated on the datasets Species1, -2 , and -3 , to be compared to the ones established on Fusion corpus. In particular we observed that the shares of species were similar regardless of the delineation strategy of the bibliometric corpora (Table A6). 
Table A4. Size of the bibliometric corpora depending on the delineation strategy.

\begin{tabular}{|c|c|c|c|c|c|c|}
\hline & \multirow{2}{*}{\multicolumn{3}{|c|}{$\begin{array}{c}\text { Delineation Strategy Kept } \\
\text { Corpus Fusion }\end{array}$}} & \multicolumn{3}{|c|}{ Alternative Delineation Strategy } \\
\hline & & & & $\begin{array}{l}\text { CORPuS } \\
\text { SPECIES1 }\end{array}$ & $\begin{array}{l}\text { Corpus } \\
\text { SPECIES2 }\end{array}$ & $\begin{array}{l}\text { CORPUS } \\
\text { SPECIES3 }\end{array}$ \\
\hline $\begin{array}{l}\text { Search query } \\
\text { applied on } \\
\text { the WoS }\end{array}$ & \multicolumn{3}{|c|}{$\begin{array}{c}\text { For most thematic corpora, species and } \\
\text { thematic terms combined with operator } \\
\text { NEAR/10. See the ten thematic search queries } \\
\text { in Appendix A. }\end{array}$} & \multicolumn{3}{|c|}{$\begin{array}{c}\text { Species terms only. SPECIES search query in } \\
\text { Appendix A. }\end{array}$} \\
\hline $\begin{array}{l}\text { Excluding } \\
\text { conditions }\end{array}$ & \multicolumn{3}{|c|}{$\begin{array}{l}\text { Some terms restrictions and wcs restrictions, } \\
\text { depending on the thematic corpus. }\end{array}$} & \multicolumn{3}{|c|}{$\begin{array}{l}\text { The same term restrictions as in Fusion, but } \\
\text { no wCs restrictions. }\end{array}$} \\
\hline $\begin{array}{l}\text { Number of } \\
\text { records } \\
\text { retrieved } \\
\text { from the } \\
\text { WoS per } \\
\text { corpus }\end{array}$ & $\begin{array}{l}\text { Genetics } \\
\text { Agronomy } \\
\text { ECOPHYSIOLOGY } \\
\text { BioticStress } \\
\text { FEEDING } \\
\text { PrOCESSING } \\
\text { Nutrition } \\
\text { AlLERGY } \\
\text { ACCEPTABILITY } \\
\text { SOCIOECONOMICS }\end{array}$ & & & \multicolumn{2}{|r|}{202,144} & \\
\hline $\begin{array}{l}\text { Indexing } \\
\text { procedure }\end{array}$ & $\begin{array}{r}\text { One occurre } \\
\text { and one occurre }\end{array}$ & $\begin{array}{l}\text { ce in the } \\
\text { nce in the }\end{array}$ & $\begin{array}{l}\text { terms } \\
\text { ic terms. }\end{array}$ & $\begin{array}{l}\text { One } \\
\text { occurrence } \\
\text { in the } \\
\text { species } \\
\text { terms and } \\
\text { one } \\
\text { occurrence } \\
\text { in the } \\
\text { thematic } \\
\text { terms. }\end{array}$ & $\begin{array}{l}\text { One } \\
\text { occurrence } \\
\text { in the } \\
\text { species } \\
\text { terms and } \\
\text { two } \\
\text { occurrences } \\
\text { in the } \\
\text { thematic } \\
\text { terms. }\end{array}$ & $\begin{array}{c}\text { Two } \\
\text { occurrences } \\
\text { in the } \\
\text { species } \\
\text { terms and } \\
\text { two } \\
\text { occurrences } \\
\text { in the } \\
\text { thematic } \\
\text { terms. }\end{array}$ \\
\hline $\begin{array}{l}\text { Number of } \\
\text { records kept } \\
\text { after } \\
\text { indexing } \\
\text { (share of } \\
\text { records kept } \\
\text { in \%) }\end{array}$ & $\begin{array}{l}\text { GeNETICS } \\
\text { AgronOMY } \\
\text { ECOPHYSIOLOGY } \\
\text { BiOTICSTRESS } \\
\text { FEEDING } \\
\text { PrOCESING } \\
\text { NutRITION } \\
\text { AlLERGY } \\
\text { ACCEPTABILITY } \\
\text { SOCIOECONOMICS }\end{array}$ & $\begin{array}{c}34,388 \\
19,070 \\
29,867 \\
20,243 \\
3654 \\
27,180 \\
15,383 \\
3650 \\
3972 \\
963\end{array}$ & $\begin{array}{l}98 \% \\
98 \% \\
98 \% \\
97 \% \\
84 \% \\
76 \% \\
91 \% \\
67 \% \\
73 \% \\
67 \%\end{array}$ & $160,238(79 \%)$ & $142,763(71 \%)$ & $100,248(50 \%)$ \\
\hline $\begin{array}{l}\text { Final } \\
\text { number of } \\
\text { records }\end{array}$ & \multicolumn{3}{|c|}{$\begin{array}{l}\text { Thematic corpora merged without duplicates: } \\
\qquad 107,823\end{array}$} & 160,238 & 142,763 & 100,248 \\
\hline
\end{tabular}


Table A5. Breakdown of the Fusion and Species3 corpora into the 10 underlying themes.

\begin{tabular}{|c|c|c|c|c|c|c|c|c|c|}
\hline \multicolumn{5}{|c|}{ FUSION Corpus } & \multicolumn{5}{|c|}{ SPECIES3 Corpus } \\
\hline $\begin{array}{c}\text { Themes } \\
\text { Index Colum } \\
\text { A }\end{array}$ & $\begin{array}{c}\text { Records } \\
\text { Number } \\
\text { Indexed with } \\
\text { a Single } \\
\text { Theme* }\end{array}$ & $\begin{array}{l}\text { Frequency } \\
\text { Ranking of } \\
\text { the Single } \\
\text { Theme }\end{array}$ & $\begin{array}{l}\text { Records } \\
\text { Number } \\
\text { Indexed with } \\
\text { the Theme of } \\
\text { Column A }\end{array}$ & $\begin{array}{l}\text { Share of } \\
\text { Themes }\end{array}$ & $\begin{array}{c}\text { Themes } \\
\text { Index Colum } \\
\text { A }\end{array}$ & $\begin{array}{c}\text { Records } \\
\text { Number } \\
\text { Indexed with } \\
\text { a Single } \\
\text { Theme * }\end{array}$ & $\begin{array}{c}\text { Frequency } \\
\text { Ranking of } \\
\text { the Single } \\
\text { Theme }\end{array}$ & $\begin{array}{l}\text { Records } \\
\text { Number } \\
\text { Indexed with } \\
\text { the Theme of } \\
\text { Column A }\end{array}$ & $\begin{array}{l}\text { Share of } \\
\text { Themes }\end{array}$ \\
\hline Genetics & 13,336 & 34,388 & 34,388 & $22 \%$ & Genetics & 35,281 & 35,281 & 35,281 & $15 \%$ \\
\hline Ecophy. & 12,841 & 29,867 & 29,867 & $19 \%$ & Ecophy. & 48,889 & 48,889 & 48,889 & $20 \%$ \\
\hline Process. & 12,049 & 27,180 & 27,180 & $17 \%$ & Process. & 30,511 & 30,511 & 30,511 & $13 \%$ \\
\hline BioticSt. & 9109 & 20,243 & 20,243 & $13 \%$ & BioticSt. & 17,839 & 17,839 & 17,839 & $7 \%$ \\
\hline Agronomy & 7982 & 19,070 & 19,070 & $12 \%$ & Agronomy & 16,789 & 16,789 & 16,789 & $7 \%$ \\
\hline Nutrition & 4866 & 15,383 & 15,383 & $10 \%$ & Nutrition & 56,021 & 56,021 & 56,021 & $23 \%$ \\
\hline Feeding & 2888 & 3654 & 3654 & $2 \%$ & Feeding & 26,296 & 26,296 & 26,296 & $11 \%$ \\
\hline Allergy & 1891 & 3650 & 3650 & $2 \%$ & Allergy & 2157 & 2157 & 2157 & $1 \%$ \\
\hline Accept. & 745 & 3972 & 3972 & $3 \%$ & Accept. & 2280 & 2280 & 2280 & $1 \%$ \\
\hline Socioeco. & 565 & 963 & 963 & $1 \%$ & Socioeco. & 3427 & 3427 & 3427 & $1 \%$ \\
\hline SUBTOTAL & \multicolumn{2}{|c|}{66,272} & & & 158370 & \multicolumn{2}{|c|}{24,946} & & \\
\hline in $\%$ & \multicolumn{2}{|c|}{$61 \%$} & 158370 & $100 \%$ & in $\%$ & \multicolumn{2}{|c|}{$25 \%$} & 239490 & $100 \%$ \\
\hline $\begin{array}{c}\text { Total FUSION } \\
\text { Corpus }\end{array}$ & \multicolumn{2}{|c|}{107823} & & & $\begin{array}{l}\text { Total } \\
\text { SPECIES3 } \\
\text { Corpus }\end{array}$ & \multicolumn{2}{|c|}{100248} & & \\
\hline
\end{tabular}


Table A6. Number and share of the records in Species1, -2 , and -3 corpora related to soya and pulses, groundnut and lathyrus-vicia broken down by periods.

\begin{tabular}{|c|c|c|c|c|c|c|c|c|c|}
\hline \multirow{2}{*}{ Family species index terms of records } & \multicolumn{3}{|c|}{ SPECIES3 } & \multicolumn{3}{|c|}{ SPECIES2 } & \multicolumn{3}{|c|}{ SPECIES1 } \\
\hline & $1980-2018$ & 1980-1999 & $2000-2018$ & $1980-2018$ & 1980-1999 & $2000-2018$ & $1980-2018$ & 1980-1999 & $2000-2018$ \\
\hline Only Soya-G1 & 42,861 & 9372 & 33,489 & 62,233 & 15,330 & 46,903 & 68,790 & 19,750 & 49,040 \\
\hline Soya-G1—and a generic term * & 533 & 108 & 425 & 1840 & 346 & 1494 & 1895 & 360 & 1535 \\
\hline Only other Pulses than PFL-G3 & 21,394 & 5401 & 15,993 & 25,268 & 7765 & 17,503 & 28,785 & 10,431 & 18,354 \\
\hline Other Pulses than PFL-G3—and a generic term & 16,755 & 5625 & 11,130 & 22,447 & 8473 & 13,974 & 26,619 & 11,412 & 15,207 \\
\hline Only PFL-G2 & 1736 & 308 & 1428 & 3851 & 684 & 3167 & 3966 & 745 & 3221 \\
\hline PFL-G2-and a generic term & 1303 & 253 & 1050 & 3111 & 656 & 2455 & 3227 & 689 & 2538 \\
\hline Subtotal Soya/Pulses & 84,582 & 21,067 & 63,515 & 118,750 & 33,254 & 85,496 & 133,282 & 43,387 & 89,895 \\
\hline \% Soya in Soya/Pulses subtotal & $51.3 \%$ & $45.0 \%$ & $53.4 \%$ & $54.0 \%$ & $47.1 \%$ & $56.6 \%$ & $53.0 \%$ & $46.4 \%$ & $56.3 \%$ \\
\hline$\%$ Soya/Pulses in corpus period & $84.4 \%$ & $85.4 \%$ & $84.0 \%$ & $83.2 \%$ & $84.8 \%$ & $82.6 \%$ & $83.2 \%$ & $85.2 \%$ & $82.2 \%$ \\
\hline Groundnut & 8491 & 1900 & 6591 & 12,133 & 2883 & 9250 & 14,268 & 4055 & 10,213 \\
\hline$\%$ Groundnut in corpus period & $8.5 \%$ & $7.7 \%$ & $8.7 \%$ & $8.5 \%$ & $7.4 \%$ & $8.9 \%$ & $8.9 \%$ & $8.0 \%$ & $9.3 \%$ \\
\hline Lathyrus or Vicia & 1374 & 310 & 1064 & 1684 & 427 & 1257 & 1907 & 539 & 1368 \\
\hline \% Lathyrus/Vicia in corpus period & $1.4 \%$ & $1.3 \%$ & $1.4 \%$ & $1.2 \%$ & $1.1 \%$ & $1.2 \%$ & $1.2 \%$ & $1.1 \%$ & $1.3 \%$ \\
\hline Corpus total for the period & 100,248 & 24,661 & 75,587 & 142,763 & 39,216 & 103,547 & 160,238 & 50,929 & 109,309 \\
\hline$\%$ period in corpus total $1980-2018$ & $100 \%$ & $25 \%$ & $75 \%$ & $100 \%$ & $27 \%$ & $73 \%$ & $100 \%$ & $32 \%$ & $68 \%$ \\
\hline Generic term only & 1745 & 364 & 1381 & 1720 & 393 & 1327 & 1804 & 412 & 1392 \\
\hline
\end{tabular}

Note: Each line in the table are excluding count from each other. PFL: pea, fababean or lupin. * Lecture: For instance, this line reports the number of records containing only a generic term and a term linked to soya in title, abstract or authors' keywords for a generic term such as legumes. 


\section{Appendix C. A Brief Overview of Grain-Legumes Domestication and Their Development}

Annual legumes (Papilionaceae/Fabaceae or Leguminosae) cultivated for their seeds are frequent companions of cereals in most parts of the world. They are attractive because, contrary to other flower plants, legumes can fix atmospheric nitrogen thanks to a symbiosis with root bacteria called Rhizobium. The cultivation of legumes helps enrich the soil with nitrogen; hence, cultivated with cereals in rotation or in association, they contribute to higher fertility in soils. Moreover, as they are rich in protein, they complement cereals in diets. This protein complementarity, allowing them to substitute for animal-based proteins, was essential for the development of traditional farming communities. As underlined in [30], each important civilization in history had their basic cereals with their companion legumes. For instance, in Western Asia and Europe, wheats and barleys were frequently cultivated with peas, lentils, chickpeas, and faba beans, while, maize with several species of beans (Phaseolus) in the Americas, more with groundnut in South America. In Africa, mil and sorgho were grown along with niebe and voandzou. Soya was added among cereals in China, lablab and mungo in India, etc.

\section{Appendix C.1. First Signs before the Common Era}

The first definite signs of domesticated plants in the Old World appeared around 10,500-10,100 years before the common era (BCE). Legumes appear frequently with cereals (wheat and barley): "several grain legumes appear as constant companions of the cereals" [30] (p.1). The most frequent pulses in the early Neolithic period in the Middle East (near the Mediterranean Basin) are lentils (Lens culinaris) and peas (Pisum sativum), and two more local legume crops are chickpeas (Cicer arietinum) and bitter vetches (Vicia ervilia). Additional legumes were cultivated later, such as grass peas (Lathyrus sativus) with some evidence in Greece and Bulgaria around 8000-7000 BCE. The origin and early spread of faba beans (Vicia faba) is less clear.

These archaeological findings reveal "a rule, not a single crop but rather a combination of cereals, pulses, and flax appears in these early farming villages. Moreover, the assemblage seems to be similar throughout the Fertile Crescent. In other words, a common package of grain crops characterizes the development of agriculture in this 'core area'" [30] (p. 2-3) on the spread of those crops over Europe and Mediterranean Basin during 10,500-20,000 BCE.

In the Mediterranean basin and Europe, evidence from the beginning of the Common Era has found on the cultivation of the fenugreeks and the lupins, as well as the grass pea and vicias. As regards the Mesoamerican area, an illustration of legumes development was the "three sisters" system (maize, beans, and squash intercropping).

\section{Appendix C.2. Antiquity Period}

Legumes with bigger grains such as we know today reached this size in the Antiquity period. Domestication of these plants brought several major changes in plant architecture, pod size, and lodging resistance. Through cultivation, the stems became sturdier and stiffer, and had a reduced propensity to climb, to make them more easily cultivable in the field. Some wild type chemical defenses had also been counter-selected to favor their consumption. Many wild legumes contain strong toxins and antimetabolites that protect them from animal predation. Gradually, the techniques of cooking and soaking or fermentation allowed the seeds to be healthy for consumption.

Roman texts report different frequencies of legumes use for human consumption. Lentils, peas, and faba beans were the most widely consumed throughout Europe and the Middle East, as well as chickpeas further south. Fenugreek was used as a condiment, especially in the Mediterranean Basin. Lupines were more concentrated around Greece and Egypt, and seems to have been domesticated later in Antiquity. Some species within the genus Vicia, having a particular taste, were consumed only during periods of famine and were reserved for medicinal purposes. Certain preferences were established for each region, still marking our culinary traditions today. For example, beans were more heavily consumed in Egypt and Spain, lentils in France. 


\section{Appendix C.3. From the Middle Ages to the Modern Period}

Productivity gains in agriculture remained very low until the agrarian revolutions of the 17th and 18th centuries in Europe. At this time, historians have found that legumes were second to cereals in consumption preferences, and in opposition to animal products. In France, for instance, paintings of the Renaissance period contrasted nobles who could go hunting with peasants reduced to eating lentils and bread [38]. It was a privilege of the nobility to consume meat more frequently, strongly linked to the right to hunt. This privilege has undoubtedly marked the collective unconscious towards a preference for the consumption of meat products, which in turn is also strongly correlated with the increase in incomes during the 20th century. Therefore, the current preference of Western countries for animal-based proteins is not only related to nutritional interest. However, consequently, high consumption of animal products makes it unnecessary to associate cereals and legumes consumption to meet protein needs.

In addition, during the succession of wars affecting Europe in the 19th and 20th centuries, legumes were frequently presented as filling foods during food shortages. Combined with a traditional image of "poor man's meat" or as a food related to famines and wars, after the Second World War consumers gave up legumes, and their consumption fell in Western countries. Trade agreements between Europe and the USA resulted in no development of soya in Europe during several decades, and thus to important soya imports for livestock.

Nowadays, Europe presents the lowest consumption with $3 \mathrm{~kg} / \mathrm{year}$ per capita. In some European countries, consumption is even less, such as France (1.7 kg/year per capita in 2011, Agreste statistics). Globally, legumes are far more used for feeding animals, but with a minor position in feed formulas compared with soya. In addition to this trend, chemical fertilizers development favored a nitrogen cycle conception in cropping system without legumes (see [9] for more insights on economic trade-offs on legumes uses).

\section{Appendix D. Corpus Broken Down by Theme and the Four Main Publishing Countries/Geographical Areas}

Only records indexed with soya or the ones indexed with pulses were included (i.e., records co-indexed with several groups of grain-legumes were excluded); proportional count linked to international records applied; a group count done for the EU28; "Others" are all identified countries other than the USA, China, India, and those belonging to the EU28. Each theme counts for the number of records indexed with this theme (with or without co-indexing theme), representing the importance of the theme. Graphs are ordered by the amount of records by themes.

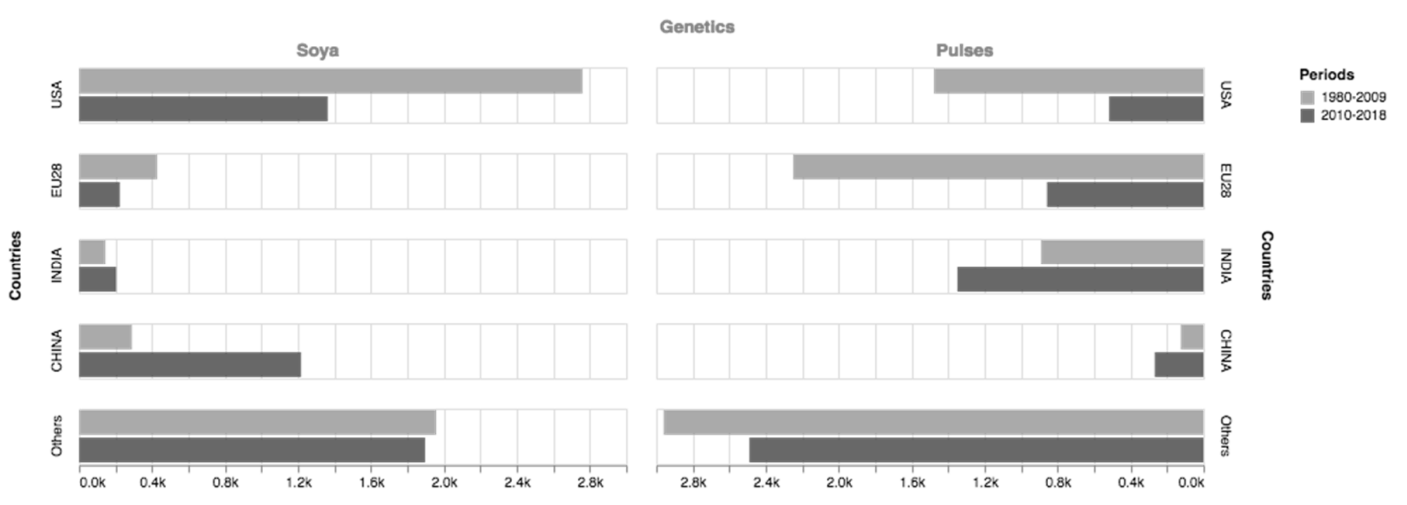

(a)

Figure A2. Cont. 


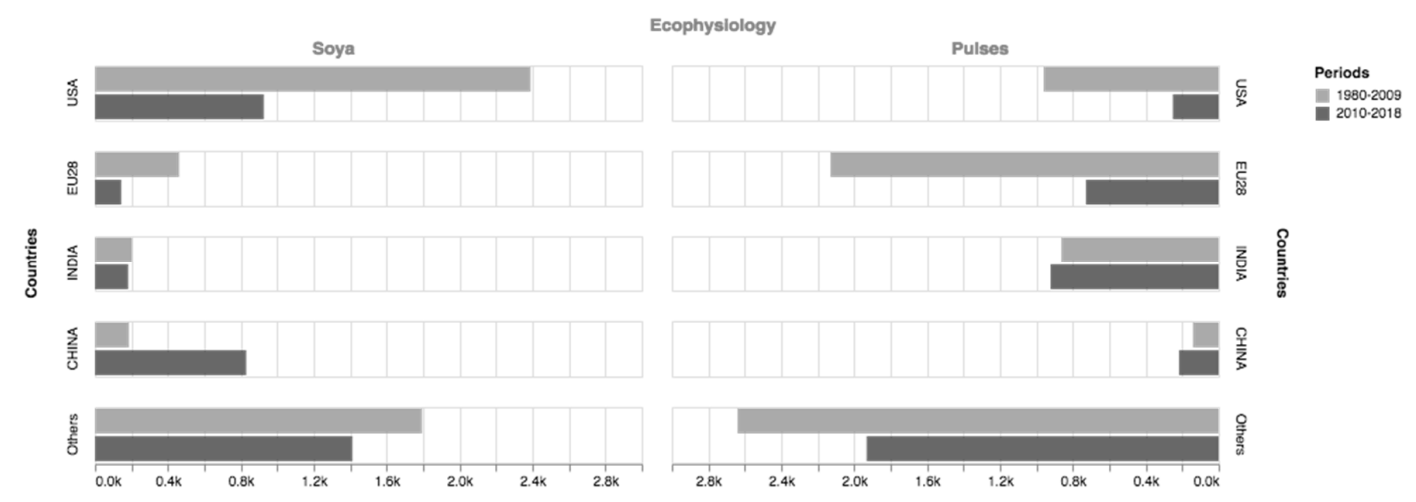

(b)

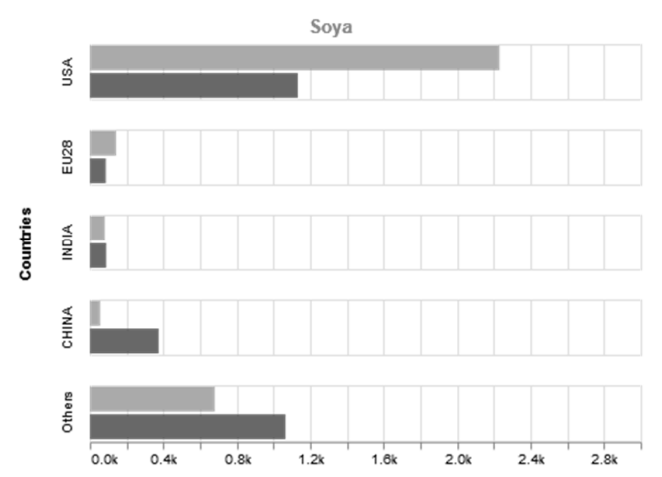

BioticStress

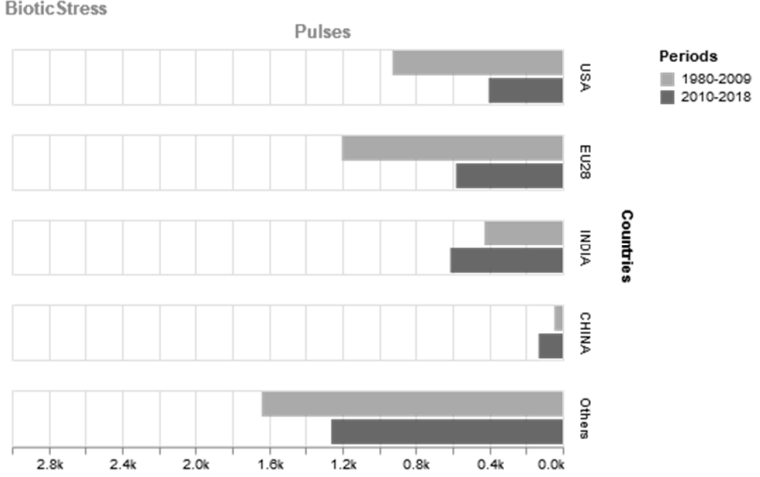

(c)
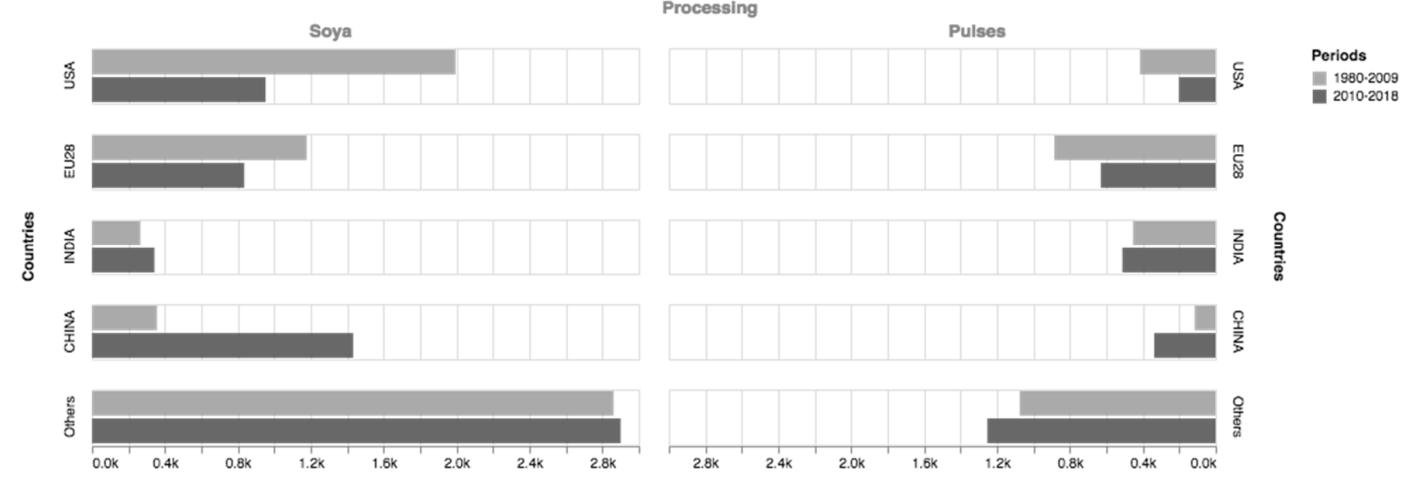

(d)
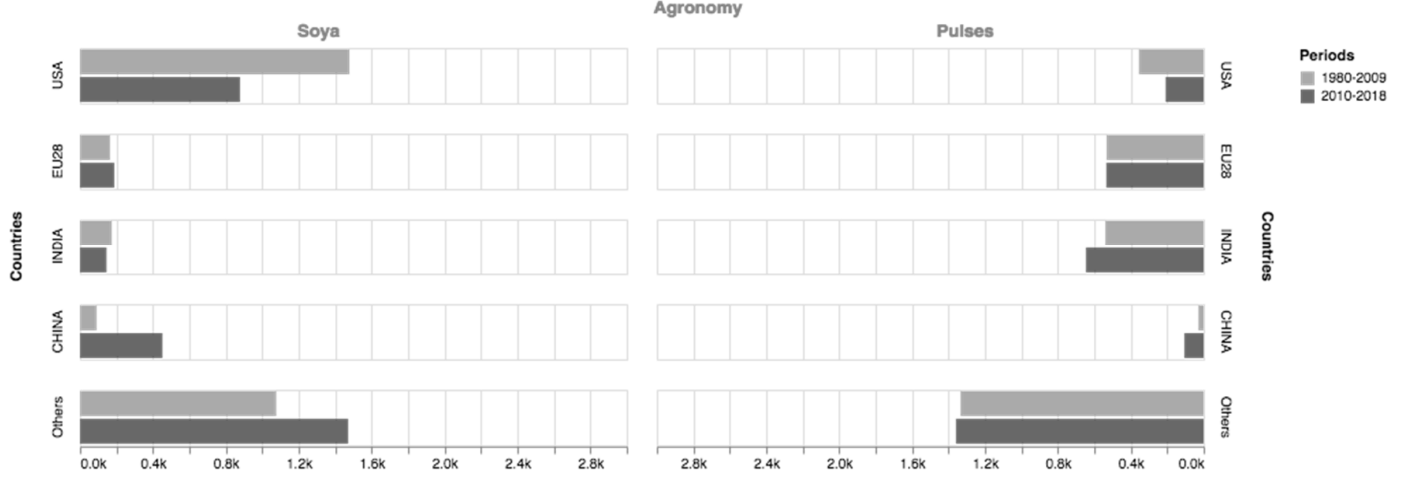

(e)

Figure A2. Cont. 


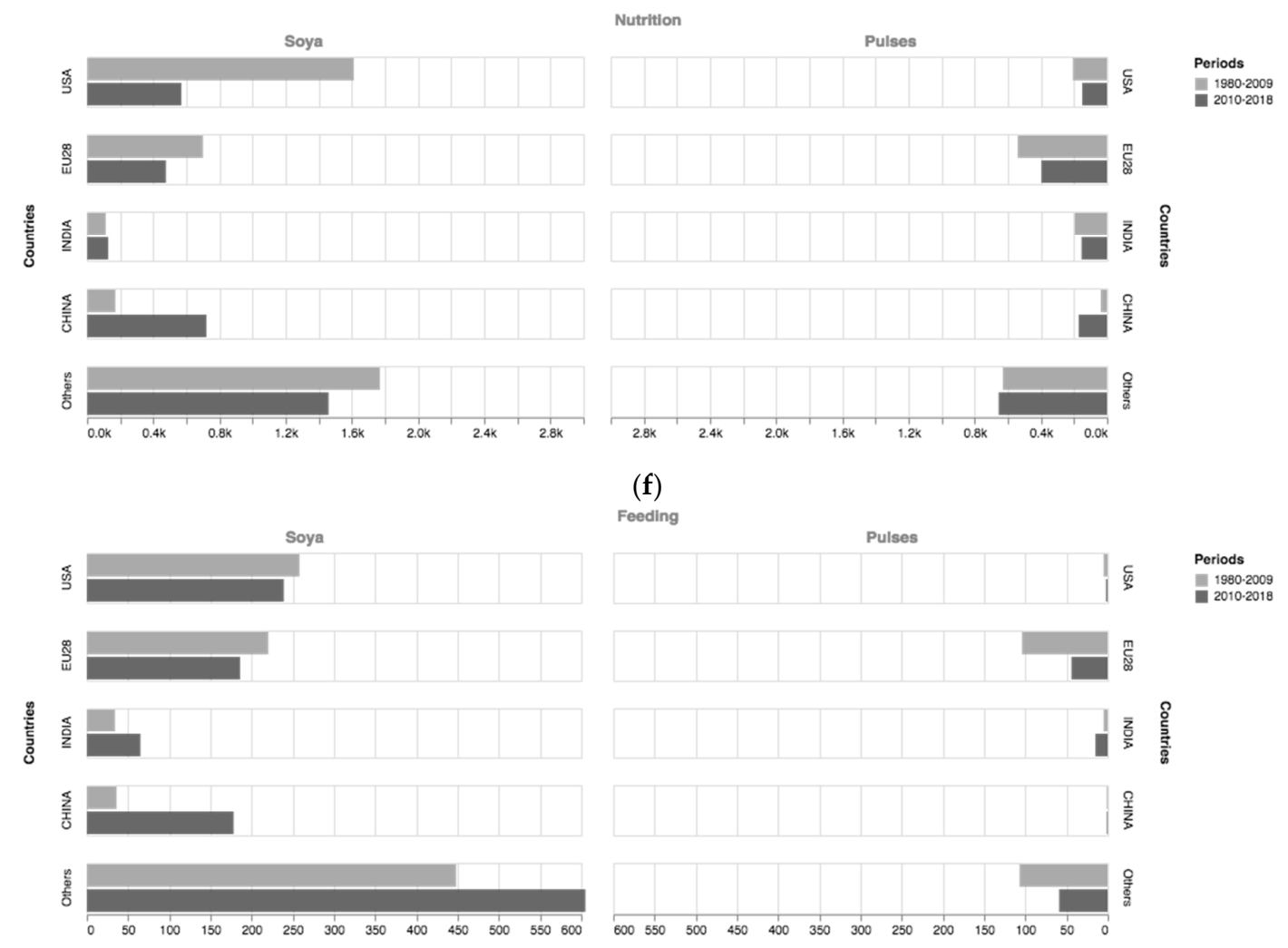

(g)
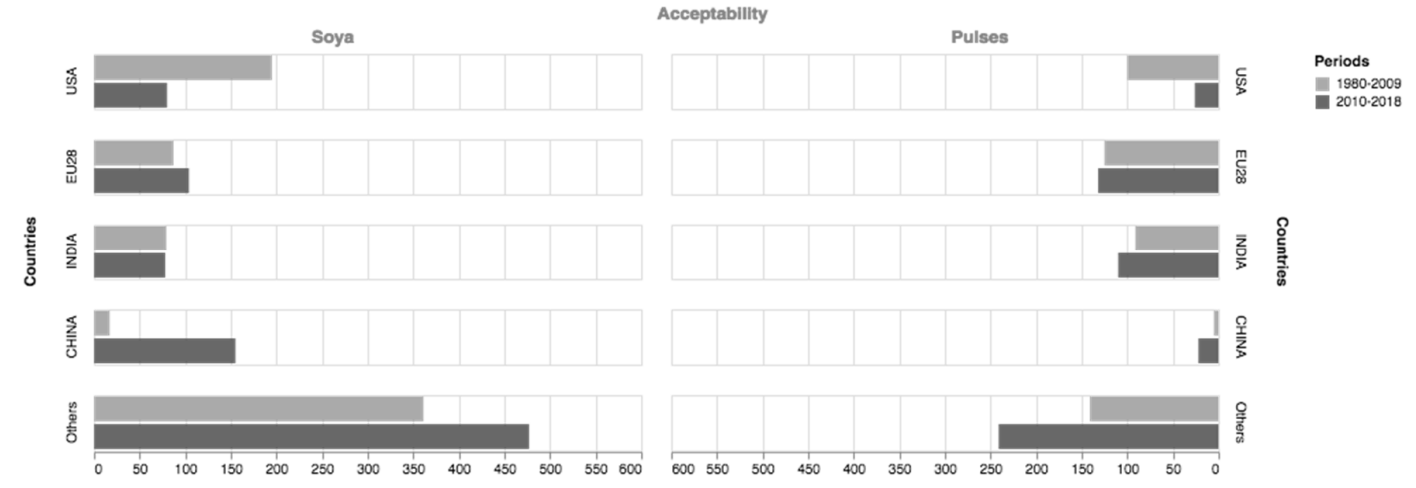

(h)
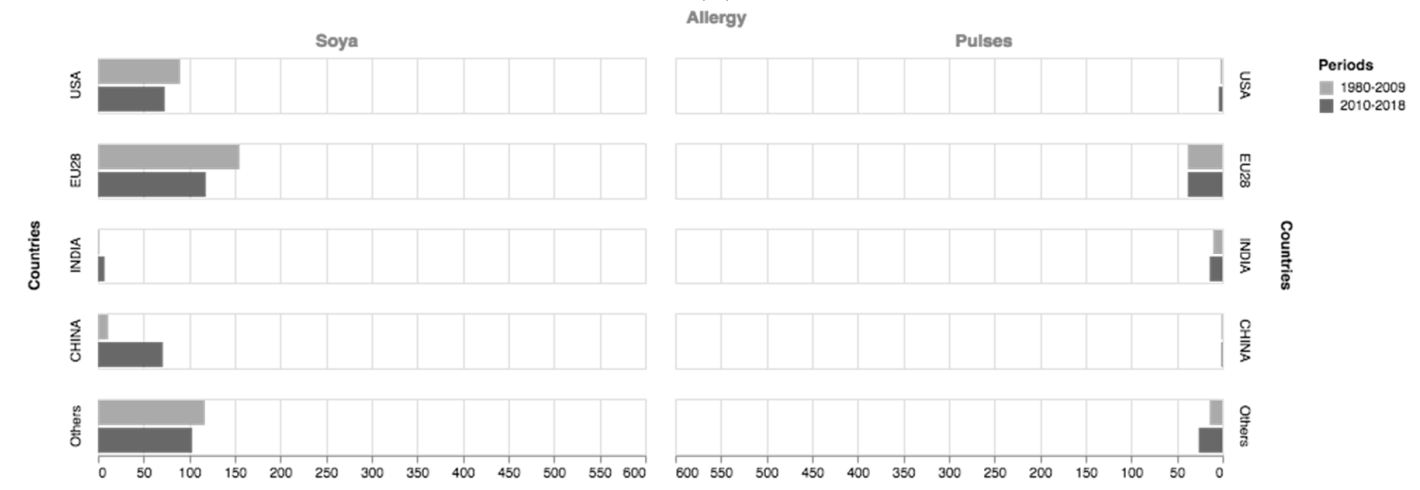

(i)

Figure A2. Cont. 


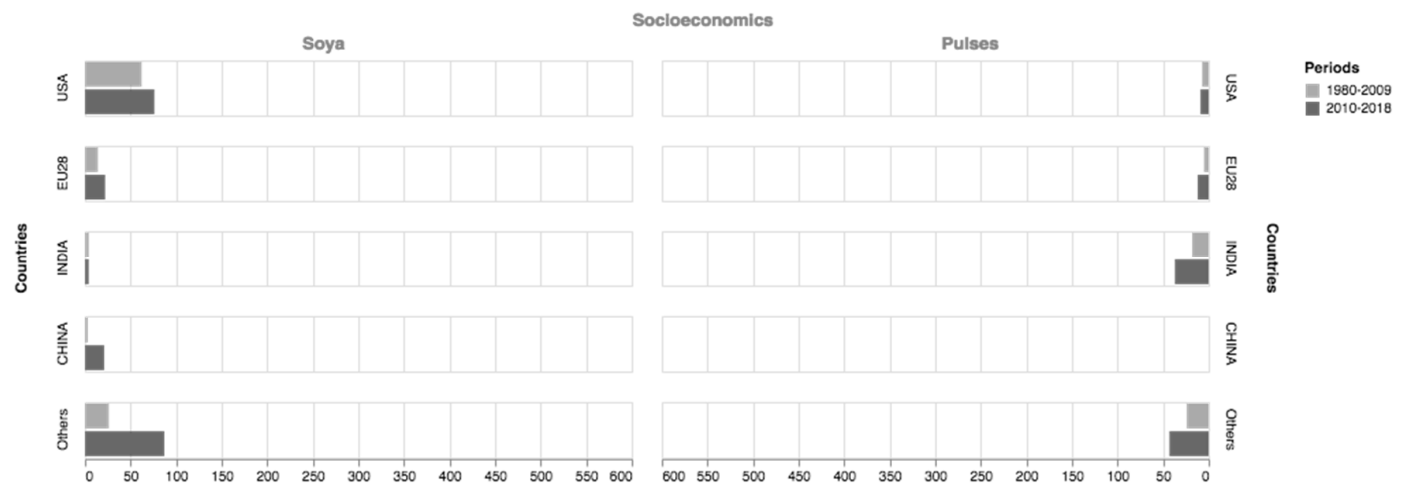

(j)

Figure A2. Records number by theme and by period for the USA, the EU28, India, China, and Others. Scale based on $3 \mathrm{k}$ for the figures $(\mathbf{a}-\mathbf{f})$, and on $0.6 \mathrm{k}$ for the figures $(\mathbf{g}-\mathbf{j})$.

\section{References}

1. Lemaire, G.; de Faccio Carvalho, P.C.; Kronberg, S.; Recous, S. (Eds.) Agroecosystem Diversity; Academic Press: Cambridge, MA, USA, 2018.

2. Meynard, J.M.; Charrier, F.; Le Bail, M.; Magrini, M.B.; Charlier, A.; Messéan, A. Socio-technical lock-in hinders crop diversification in France. Agron. Sustain. Dev. 2018, 38, 54. [CrossRef]

3. Frison, E.A.; Cherfas, J.; Hodgkin, T. Agricultural biodiversity is essential for a sustainable improvement in food and nutrition security. Sustainability 2011, 3, 238-253. [CrossRef]

4. Peoples, M.B.; Hauggaard-Nielsen, H.; Huguenin-Elie, O.; Jensen, E.S.; Justes, E.; Williams, M. The Contributions of Legumes to Reducing the Environmental Risk of Agricultural Production. In Agroecosystem Diversity; Lemaire, G., de Faccio Carvalho, P.C., Kronberg, S., Recous, S., Eds.; Academic Press: Cambridge, MA, USA, 2018; pp. 123-143.

5. Rawal, V.; Bansal, V.; Thokchom, D. Biodiversity for Food and Agriculture and Food Security. An Exploration of Interrelationships, Background Study Paper NO. 69-2019, FAO Commission on Genetic Resources for Food and Agriculture. Available online: http://www.networkideas.org/wp-content/uploads/2019/02/ca3218en.pdf (accessed on 25 July 2019).

6. Weiner, J. Applying plant ecological knowledge to increase agricultural sustainability. J. Ecol. 2017, 105, 865-870. [CrossRef]

7. Magrini, M.-B.; Anton, M.; Chardigny, J.-M.; Duc, G.; Duru, M.; Jeuffroy, M.-H.; Meynard, J.-M.; Micard, V.; Walrand, S. Pulses for sustainability: Breaking agriculture and food sectors out of lock-in. Front. Sustain. Food Syst. 2018, 2, 64. [CrossRef]

8. Magrini, M.-B.; Befort, N.; Nieddu, M. Technological Lock-In and Pathways for Crop Diversification in the Bio-Economy. In Agroecosystem Diversity; Lemaire, G., de Faccio Carvalho, P.C., Kronberg, S., Recous, S., Eds.; Academic Press: Cambridge, MA, USA, 2019; pp. 375-388.

9. Magrini, M.B.; Anton, M.; Cholez, C.; Corre-Hellou, G.; Duc, G.; Jeuffroy, M.H.; Meynard, J.M.; Pelzer, E.; Voisin, A.-S.; Walrand, S. Why are grain-legumes rarely present in cropping systems despite their environmental and nutritional benefits? Analyzing lock-in in the French agrifood system. Ecol. Econ. 2016, 126, 152-162. [CrossRef]

10. Rawal, V.; Navarro, D.K. The Global Economy of Pulses; FAO: Rome, Italy, 2017.

11. Watson, C.A.; Reckling, M.; Preissel, S.; Bachinger, J.; Bergkvist, G.; Kuhlman, T.; Lindström, K.; Nemecek, T.; Topp, C.F.; Vanhatalo, A.; et al. Grain legume production and use in European agricultural systems. Adv. Agron. 2017, 144, 235-303.

12. Dosi, G.; Nelson, R.R. Technical Change and Industrial Dynamics as Evolutionary Processes. In Handbook of the Economics of Innovation; Hall, B.H., Rosenberg, N., Eds.; Elsevier: Standford, CA, USA, 2010; Volume 1, pp. 51-127.

13. Rogers, E.M. Diffusion of Innovations; Free Press: New York, NY, USA, 2003. 
14. Callon, M.; Law, J.; Rip, A. Mapping the Dynamics of Science and Technology; Palgrave Macmillan: London, UK, 1986.

15. Noyons, E.C.M. Science Maps within a Science Policy Context. In Handbook of Quantitative Science and Technology Research, the use of Publication and Patent Statistics in Studies of SET Systems; Moed, H., Glänzel, W., Schmoch, U., Eds.; Kluwer Academic Publishers: Dordrecht, The Netherlands, 2004; pp. 237-255.

16. Noyons, E. Bibliometric mapping of science in a policy context. Scientometrics 2001, 50, 83-98. [CrossRef]

17. Rafols, I.; Hopkins, M.M.; Hoekman, J.; Siepel, J.; O’Hare, A.; Perianes-Rodríguez, A.; Nightingale, P. Big Pharma, little science: A bibliometric perspective on Big Pharma's R\&D decline. Technol. Forecast. Soc. Chang. 2010, 81, 22-38.

18. Barbier, M.; Bompart, M.; Garandel-Batifol, V.; Mogoutov, A. Textual Analysis and Scientometric Mapping of the Dynamic Knowledge in and around the IFSA Community. In Farming Systems Research into the 21st Century: The New Dynamic; Springer: Cham, The Netherlands, 2012; pp. 73-94.

19. Glänzel, W.; Moed, H.F.; Schmoch, U.; Thelwall, M. Springer Handbook of Science and Technology Indicators; Springer: Basel, Switzerland, 2019. [CrossRef]

20. Zitt, M.; Lelu, A.; Cadot, M.; Cabanac, G. Bibliometric Delineation of Scientific Fields. In Springer Handbook of Science and Technology Indicators; Springer: Basel, Switzerland, 2019; pp. 25-68. [CrossRef]

21. Meyer, E.T.; Schroeder, R. Untangling the web of e-Research: Towards a sociology of online knowledge. J. Informetr. 2009, 3, 246-260. [CrossRef]

22. Wyatt, S.; Milojević, S.; Park, H.; Leydesdorff, L. Quantitative and Qualitative STS: The Intellectual and Practical Contributions of Scientometrics, SSRN 2015. Available online: https://ssrn.com/abstract=2588336 (accessed on 12 February 2019).

23. Cecere, G.; Martinelli, A. Drivers of knowledge accumulation in electronic waste management: An analysis of publication data. Res. Policy 2017, 46, 925-938. [CrossRef]

24. Minguillo, D.; Tijssen, R.; Thelwall, M. Do science parks promote research and technology? A scientometric analysis of the UK. Scientometrics 2015, 102, 701-725. [CrossRef]

25. Tancoigne, E.; Barbier, M.; Cointet, J.P.; Richard, G. The place of agricultural sciences in the literature on ecosystem services. Ecosyst. Serv. 2014, 10, 35-48. [CrossRef]

26. Martín-Martín, A.; Orduna-Malea, E.; López-Cózar, E.D. Coverage of highly-cited documents in Google Scholar, Web of Science, and Scopus: A multidisciplinary comparison. Scientometrics 2018, 116, 2175-2188. [CrossRef]

27. Johnson, R.; Watkinson, A.; Mabe, M. The STM Report, 5th ed.; An Overview of Scientific and Scholarly Publishing; International Association of Scientific, Technical and Medical Publishers: Hague, The Netherlands, 2018.

28. European Commission. Report from the Commission to the Council and the European Parliament on the Development of Plant Proteins in the European Union, COM 757. Brussels. Available online: https://ec.europa.eu/info/sites/info/files/food-farming-fisheries/plants_and_plant_products/ documents/report-plant-proteins-com2018-757-final_en.pdf (accessed on 5 December 2018).

29. Garfield, E.; Sher, I.H. KeyWords Plus ${ }^{\mathrm{TM}}$ _Algorithmic derivative indexing. J. Am. Soc. Inf. Sci. 1993, 44, 298-299. [CrossRef]

30. Zohary, D.; Hopf, M.; Weiss, E. Domestication of Plants in the Old World: The Origin and Spread of Domesticated Plants in Southwest Asia, Europe, and the Mediterranean Basin, 4th ed.; Oxford University Press: Oxford, UK, 2012.

31. Aykroyd, W.R.; Doughthy, J. Les graines de légumineuses dans l'alimentation humaine; Organisation des Nations-Unies pour l'Alimentation et l'agriculture: Rome, Italy, 2008.

32. Sonnino, A. Leguminose da Granella e Ricerca Agricola-Pulses and Agricultural Research. Atti del Seminario Leguminose da Granella—Sant'Angelo Lodigiano. 14 October 2016, pp. 45-50. Available online: https://sites.google.com/site/storiagricoltura/download-area/atti_seminari_mulsa (accessed on 5 July 2018).

33. Lascialfari, M.; Magrini, M.-B.; Triboulet, P. The drivers of product innovations in pulse-based foods: Insights from case studies in France, Italy and USA. J. Innov. Econ. Manag. 2019, 1, 111-143. [CrossRef]

34. Sabaté, J. (Ed.) Environmental Nutrition. In Connecting Health and Nutrition with Environmentally Sustainable Diets, 1st ed.; Academic Press: Cambridge, MA, USA, 2019. 
35. Sivasankar, S.; Ellis, N.; Buruchara, R.; Henry, C.; Rubiales, D.; Sandhu, J.S.; Negra, C. 10-year Research Strategy for Food Crops. 2016. Available online: https://pulses.org/future-of-food/10-year-research-strategy (accessed on 9 August 2019).

36. Meynard, J.M.; Jeuffroy, M.H.; Le Bail, M.; Lefèvre, A.; Magrini, M.B.; Michon, C. Designing coupled innovations for the sustainability transition of agrifood systems. Agric. Syst. 2017, 157, 330-339. [CrossRef]

37. Ciarli, T.; Ràfols, I. The relation between research priorities and societal demands: The case of rice. Res. Policy 2019, 48, 949-967. [CrossRef]

38. Quellier, F. Petite et grande histoire des légumineuses en Occident, Journées de la Fondation Louis Bonduelle, Paris, 2016. Available online: http://www.fondation-louisbonduelle.org/wp-content/uploads/2016/10/ florent-quellier-histoire-des-legumineuses-rencontres-fondation-louis-bonduelle-legumes-secs-proteinesvegetales.pdf (accessed on 29 July 2019).

(C) 2019 by the authors. Licensee MDPI, Basel, Switzerland. This article is an open access article distributed under the terms and conditions of the Creative Commons Attribution (CC BY) license (http://creativecommons.org/licenses/by/4.0/). 